$\mathcal{G S}_{\text {https://doi.org/10.3765/sp.10.12 }}^{\text {Semantics \& Pragmatics Volume 10, Article 12, } 2017}$

This is an EARLY ACCESS version of

Schlenker, Philippe. 2017. Super monsters II: Role Shift, iconicity and quotation in sign language. Semantics and Pragmatics 10(12). 1-67. https: //doi.org/10.3765/sp.10.12.

This version will be replaced with the final typeset version in due course. Note that page numbers will change, so cite with caution. 
EARLY ACCESS

\title{
Super monsters II: Role Shift, iconicity and quotation in sign language*
}

\author{
Philippe Schlenker ${ }^{\dagger}$ \\ Institut Jean-Nicod, CNRS \\ New York University
}

Submitted 2016-01-29 / First decision 2016-06-08 / Revision received 2016-07-28 / Second

decision 2016-07-28 / Accepted 2017-03-28 / Early access 2017-08-01

\begin{abstract}
While sign language 'Role Shift' can be analyzed as an overt instance of context shift, we argue that it has two broad properties that require a special treatment. First, Role Shift used to report attitudes ('Attitude Role Shift') has a quotational component which does not follow from a simple context-shifting analysis. Second, Role Shift used to report actions ('Action Role Shift') has a strong iconic component: properties of signs that can be assigned to the reported situation (e.g. a happy face) must be so interpreted. We argue that both varieties of Role Shift should be analyzed as context shift, but with an important addition: the expressions that appear under Role Shift should be interpreted maximally iconically, i.e. so as to maximize the possibilities of projection between the signs used and the situation they make reference to (Role Shift is thus a 'super monster' not just in that it can shift the context outside of attitude reports, as was argued in Part I, but also in that it has an iconic and thus hyperintensional component). This accounts both for
\end{abstract}

* ASL consultant for this article: Jonathan Lamberton. Special thanks to Jonathan Lamberton, who has provided exceptionally fine-grained data throughout this research; his contribution as a consultant has been considerable. He also provided and/or checked ASL transcriptions and translations.

LSF consultant for this article: Ludovic Ducasse. Special thanks also to Ludovic Ducasse, who has provided very detailed judgments on complex sentences throughout this research.

Thanks to Kathryn Davidson and to audiences at NYU for helpful suggestions. Special thanks to three referees for Semantics \& Pragmatics, to Sandro Zucchi, and to David Beaver for extremely detailed and helpful comments. The references were prepared by Lucie Ravaux, who also checked the computation of average judgments given with example sentences. Special thanks to Amir Anvari for doing the .doc to .tex conversion, for improving the typography, and for catching several typos. The research leading to these results received funding from the European Research Council under the European Union's Seventh Framework Programme (FP/2007-2013) / ERC Grant Agreement N³24115-FRONTSEM (PI: Schlenker). Research was conducted at Institut d'Etudes Cognitives (ENS), which is supported by grants ANR-10-IDEX-0001-02 PSL* and ANR-10-LABX-0087 IEC. The research reported in this piece also contributes to the COST Action IS1006.

$\dagger$ Institut Jean-Nicod - CNRS, UMR 8129, ENS/EHESS - PSL Research University F-75005 Paris, France. 
the quotational character of Attitude Role Shift (in this case, maximal iconicity reduces to quotation), and for the fact that Action Role Shift has a strong iconic component. Finally, this analysis vindicates the view that some expressions may be simultaneously used and mentioned/demonstrated, as argued for instance in Recanati 2001.

Keywords: monsters, context shift, Role Shift, Action Role Shift, Attitude Role Shift

\section{Introduction}

Role Shift in sign language can be taken to be an overt instance of context shift, as argued in Quer 2005. In Part I of the present piece, we suggested that two varieties of Role Shift should be distinguished: Attitude Role Shift resembles context-shifting phenomena that have been described in indirect discourse in some spoken languages, and we arguably find the same typology of context-shifting operations within the signed and spoken modalities (in both cases, some constructions allow for 'mixing of perspectives' under attitude operators, while others require that indexicals 'shift together'). Action Role Shift has no uncontroversial counterpart in spoken languages, and it arises in extensional environments. In cases that have been studied in spoken language, operators that shift the context of evaluation of indexicals - 'monsters', in the established terminology — are limited to attitude reports (see for instance Schlenker 2011). Because Role Shift can shift the context of evaluation of indexicals in a broader set of environments, we called it a 'super monster' in Part I. Still, while Action Role Shift has some of the same overt characteristics as Attitude Role Shift, in ASL and LSF it affects indexicals in a different way: all the indexicals discussed in Part I were acceptable — and had to be shifted — under Attitude Role Shift; by contrast, under Action Role Shift most indexicals triggered an attitude reinterpretation or where deviant, while the first person agreement marker was acceptable without such a reinterpretation and received a shifted meaning.

We argue in this piece that the context-shifting analysis is insufficient, and that (ASL and LSF) Role Shift has two broad properties that require a special treatment. First, Attitude Role Shift has a quotational component which does not follow from a simple context-shifting analysis. Second, Action Role Shift has a strong iconic component: properties of signs that can be assigned to the reported situation must be so interpreted - for instance, under Action Role Shift a happy face on the part of the signer is assigned to the character whose perspective is being reported. We maintain that both varieties of Role Shift should be analyzed as context shift, but with an important addition: expressions that appear under Role Shift should be interpreted maximally iconically, i.e. so as to maximize the possibilities of projection between 
the signs used and the situations they make reference to. This is thus a second sense in which Role Shift is a 'super monster': it doesn't just shift contexts but comes with iconic conditions in addition. We argue that quotation can be seen as a special and particularly stringent case of iconicity, and that our condition of Maximal Iconicity can thus capture properties of both Attitude and Action Role Shift. As a result, this analysis vindicates the view that some expressions may be simultaneously used and mentioned/demonstrated, as argued for instance in Recanati 2001. (For a discussion of our elicitation methods and transcription conventions, see the beginning of Part I. When judgments by our consultants are mentioned and do not already appear in Part I, the full ratings appear in Appendix IV. As was noted at the beginning of Part I, no theoretical decisions should be read into the translations of our examples, which were chosen to maximize clarity; this holds in particular for the choice between direct and indirect discourse.)

\section{The Quotational Dimension of Attitude Role Shift in ASL and LSF}

With respect to Attitude Role Shift, we already saw in Part I that in LSF our consultant disliked wh-extraction out of a role-shifted clause. In ASL, our consultant allowed for wh-extraction out of role-shifted clauses, which suggested that the latter were not just standard quotations. But this did not exclude the possibility that Attitude Role Shift still has a quotational component. ${ }^{1}$ We show in this section that in ASL and LSF alike, Attitude Role Shift displays genuine quotational effects; we will argue in the end that the context-shifting analysis must be supplemented with an iconic component, a special case of which yields (full or partial) quotation.

\subsection{ANY in ASL}

As summarized in Part I, in Zazaki wh-extraction tests and NPI licensing tests converged to suggest that indexicals can have a shifted interpretation within indirect discourse (Anand \& Nevins 2004, Anand 2006). Both tests were intended to block direct discourse readings of the embedded clause by creating a grammatical dependency between an element of the embedded clause (a trace in (1a), a Negative Polarity Item (NPI) in (1b)) and a licenser in the superordinate clause (who in (1a),

1 In addition, we showed in Appendix II of Part I that in ASL $w h$-extraction is equally possible out of embedded clauses preceded by a sign glossed as " ", which appears to specifically introduce quotations. As an anonymous referee points out, an alternative theoretical direction would be to posit that despite received wisdom extraction out of quotations is sometimes grammatical. But if so, one would need to re-analyze the data (from English and other languages) in which wh-extraction out of quotations is sharply unacceptable (see Anand 2006 p. 82 fn. 24 for possible extraction data out of quotations in Right Node Raising constructions in English; and see Anand 2006 pp. 86 sqq. for an argument that Zazaki shifted indexicals do not even involve partial quotation). 
not in (1b)). In English, such dependencies 'do not cross quotation marks', as shown by the ungrammaticality of (1a') and (1b'). In Zazaki, sentences roughly similar to (1a) and (1b) were acceptable, but unlike their (indirect discourse) counterparts in English, they allowed for readings on which I referred to the speaker of the reported speech act. This observation was crucial to argue that some Zazaki embedded clauses allow for context shift.

(1) a. The girl who Hesen said I kissed $\mathbf{t}$ is pretty.

a'. \#The girl who Hesen said 'I kissed' is pretty. ${ }^{2}$

b. Rojda didn't say I have ever lied.

b'. \#Rojda didn't say 'I have ever lied'.

As mentioned, the $w h$-extraction test did not yield the same results for our ASL consultant ('acceptable') and for our LSF consultant ('unacceptable'). But when it comes to the NPI test, our ASL consultant's judgments are squarely compatible with a quotational analysis. While his use of $A N Y$ is strongly indicative of an NPI behavior, he finds clear contrasts between $A N Y$ in standard indirect discourse, where it can be licensed, and under Attitude Role Shift, where it cannot be. We will take this to suggest that Attitude Role Shift in ASL does have a quotational component.

\subsubsection{The NPI behavior of $A N Y$}

In order to get the investigation going, we first need to establish that for our consultant $A N Y$ does have NPI uses. The following paradigm strongly suggests that in our ASL consultant's dialect ANY HEART-SOFT does indeed display the behavior of an NPI: it is acceptable when it appears in a downward-entailing environment, as in (2a) and (3a), but not in controls where the environment is positive, as in (2b) and (3b). ${ }^{3}$ (As in Part I, judgments are on a 7-point scale, with $1=$ worst and $7=$ best.)

2 In this case, the sentence could be acceptable, but on a non-quotational reading (without quotation marks) on which I refers to the actual speaker. As noted by David Beaver (p.c.), if we add to the quoted clause a device that rules out an indirect discourse reading, the resulting sentence is deviant, as expected:

(i) \#The girl who Hesen said 'I hereby promise to kiss' is pretty.

3 As is the case with English any, the existence of negative polarity uses does not rule out the existence of other uses as well, such as free choice ones. We constructed our examples with this issue in mind, which is why we selected an expression - HEART-SOFT — which could not plausibly give rise to free choice readings. 
Super monsters II

(2) IX-a JOHN OFTEN MEET-MEET [INJURED PEOPLE] $]_{b}$, 'John often meets injured people,

a. 6 BUT IX-a NEVER SHOW-b ANY HEART-SOFT. but he never shows them any kindness.'

a'. 7 BUT IX-a NEVER SHOW-b HEART-SOFT. but he never shows them kindness.'

b. 2.7 IX-a OFTEN SHOW-b ANY HEART-SOFT.

b'. 7 IX-a OFTEN SHOW-b HEART-SOFT. and he often shows them kindness.'

(ASL, 14, 123)

(3) a. 7 IX-1 NEVER SHOW BILL ANY HEART-SOFT.

'I never show Bill any kindness.'

a'. 7 IX-1 NEVER SHOW BILL HEART-SOFT.

'I never show Bill kindness.'

b. 2.3 IX-1 SHOW BILL ANY HEART-SOFT.

b'. 6.3 IX-1 SHOW BILL HEART-SOFT.

'I show Bill some kindness.'

(ASL, 14, 131)

\subsubsection{ANY in Attitude Reports: Standard Indirect Discourse vs. Attitude Role Shift}

Unsurprisingly, $A N Y$ can appear in standard indirect discourse if its environment is downward-entailing — although this is somewhat ((4a)) or slightly ((5a)) dispreferred relative to a version without $A N Y$ ((4a') and (5b') respectively). Furthermore, when $A N Y$ is in a positive environment, as in (4b) and (5b), it is rather unacceptable.

(4) IX-a JOHN OFTEN MEET-MEET [INJURED PRISONER] $]_{b}$, 'John often meets injured prisoners,
a. 5.3 BUT IX-a NEVER SAY IX-a SHOW-b ANY HEART-SOFT. but he never says he shows them any kindness.'
a'. 7 BUT IX-a NEVER SAY IX-a SHOW-b HEART-SOFT. but he never says he shows them kindness.'
b. 3 IX-a OFTEN SAY IX-a SHOW-b ANY HEART-SOFT.
b'. 7 IX-a OFTEN SAY IX-a SHOW-b HEART-SOFT. and he often says he shows them kindness.'
(ASL, 14, 127) 


\section{(5) [PRISON GUARD $]_{\mathrm{a}}$ OFTEN MEET-MEET [INJURED PRISONERS $]_{\mathrm{b}}$,} 'Prison guards often meet injured prisoners,

a. 6 BUT [NO GUARD ] SAY IX-a SHOW-b ANY HEART-SOFT. '... but no guard said he ${ }^{4}$ showed them any kindness.'

a'. 7 BUT [NO GUARD] $]_{\mathrm{a}}$ SAY IX-a SHOW-b HEART-SOFT. '... but no guard said he showed them kindness.'

\section{b. 2 [SOMEONE GUARD] a SAY IX-a SHOW-b ANY HEART-SOFT. \\ b'. 6.7 [SOMEONE GUARD] a SAY IX-a SHOW-b HEART-SOFT.} '... and some guard said he showed them kindness.' (ASL, 14, 133)

Crucially, however, the facts are different under Attitude Role Shift: there $A N Y$ is degraded even when it appears in the scope of a negative operator. This is shown by the deviance of (6a) (embedding under NEVER) and (7a) (embedding under NO GUARD). (Note that in (7) Role Shift appears to start on $S A Y$; our consultant mentions that whether or not this is the case doesn't seem to influence his judgments here, but see Koulidobrova \& Davidson 2015.)

(6) IX-a JOHN OFTEN MEET-MEET [INJURED PEOPLE $]_{\mathrm{a}}$, 'John often meets injured people,
a. 2.7 BUT IX-a NEVER SAY
$\mathrm{RS}_{\mathrm{a}}$
$\mathrm{RS}_{\mathrm{a}}$
a'. 6 But IX-a NEVER SAY IX-1 SHOW-b HEART-SOFT. IX-1 SHOW-b ANY HEART-SOFT. but he never says to them: "I show (you) (my) kindness."
b. $\quad 2.3$ IX-a OFTEN SAY
$\mathrm{RS}_{\mathrm{a}}$
b'. 6.7 IX-a OFTEN SAY IX-1 SHOW-b ANY HEART-SOFT. $\mathrm{RS}_{\mathrm{a}}$ and he often says to them: "I show (you) (my) kindness." (ASL, 14, 129)

(7) [PRISON GUARD $]_{\mathrm{a}}$ OFTEN MEET-MEET [INJURED PRISONERS $]_{\mathrm{b}}$, 'Prison guards often meet injured prisoners,
a. 3.7 BUT [NO GUARD $]_{\mathrm{a}}$
$\mathrm{RS}_{\mathrm{a}}$
$\overline{\text { SAY }}$
IX-1 SHOW-b ANY HEART-SOFT.

4 Since the locus $a$ appears both on PRISON GUARD and on NO GUARD, one could imagine that the pronoun $I X$ - $a$ doesn't serve as a variable bound by $N O G U A R D$, but is coreferential with the plural PRISON GUARD (this would be a case of locus re-use, of a sort discussed in Kuhn 2015). But our consultant confirms that the bound variable reading translation is correct, hence: no guard said he showed them any kindness, rather than no guard said they [= the guards] showed them any kindness. 
Super monsters II

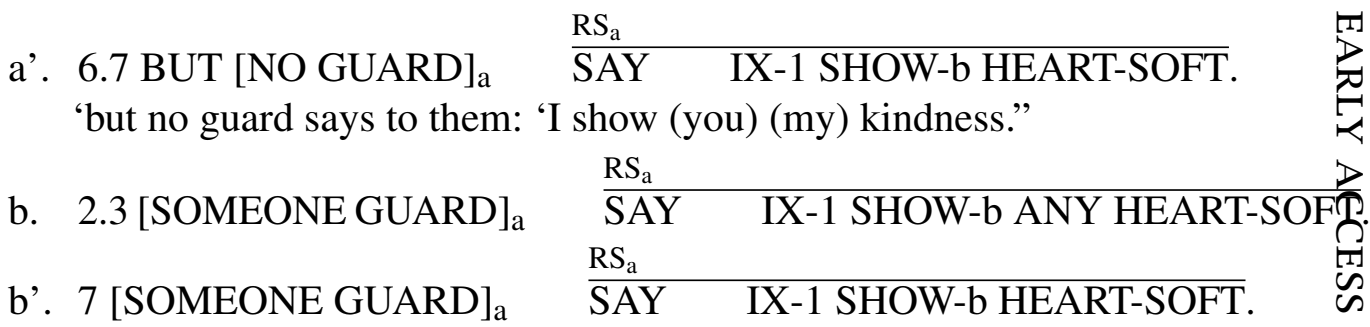
'and some guard says to them: 'I show (you) (my) kindness."

(ASL, 14, 135)

It is clear that these data raise questions about the non-quotational status of the embedded clause. They could be interpreted in at least two ways.

- One possibility is that in ASL some elements of a role-shifted clause under an attitude verb are obligatorily quoted, and that ANY HEART-SOFT belongs to that category. ${ }^{5}$ On this view, (6a) and (7a) are deviant for the same reason that the quoted sentences in (8a) and (8b) are: these statements end up denying that the relevant individuals used an ungrammatical sentence, which is not useful outside of metalinguistic contexts (this is why we mark (8a) and (8b) as (\#): they are deviant to express the meanings obtained in (8a') and (8b'), but metalinguistic contexts can be found in which they make good sense).

(8) a. (\#) John never said: 'I showed any kindness'.

a'. John never said that he showed any kindness.

b. (\#) None of the guards said: 'I showed any kindness'.

b'. None of the guards said that he showed any kindness.

A comment made by our consultant about (6b) highlights the plausibility of this hypothesis: he explicitly noted that if the relevant guard had used an ungrammatical sentence, then the report with the role-shifted clause would have been acceptable in this case. ${ }^{6}$

5 We write some rather than all elements because our consultant allows for wh-extraction out of role-shifted clauses, which suggests that $w h$-traces don't have to be quoted; this could be because they are covert, but as we discuss in Section 2.2 elided VPs are equally covert but do give rise to quotational effects. Alternatively, one could pursue a syntactic analysis without traces - but one would need to find some difference between $w h$-constructions and ellipsis, which does give rise to quotational readings.

6 Specifically, he entered in the written version of the judgment task: '[the] judgment for b is based on grammaticality of the entire sentence including John's comment. In real life, if someone made a nongrammatical comment and I quoted it, my entire utterance would be ok, since I'm preserving the nongrammatical quote as it was actually said. However, in this case I judged based on the grammaticality of the quote itself too' [JL 12.10.18]. 
- An alternative is that the NPI ANY-HEARTSOFT is unacceptable because it fails to be licensed. Why this might be so is not clear; but it must be noted that in (negative) Action Role Shift, where quotation cannot be at issue, the same NPI is also deviant. This raises the possibility that Action Role Shift — and possibly Attitude Role Shift as well — create an 'intervention effect' on the licensing of NPIs. Relevant data and a possible analysis are discussed in Appendix A.

\subsection{Ellipsis in ASL and LSF}

A consequence of the fact that grammatical dependencies 'do not cross quotation marks' is that VP-ellipsis cannot really be licensed from outside a quotation. Thus there is a contrast between (9a) and (9b):

(9) Context: The speaker has recently had a political conversation with John. The addressee and John have never met each other.

a. You love Obama. John told me that he doesn't.

$\Rightarrow$ no inference about the precise words John used

b. (\#) You love Obama. John told me: 'I don't.'

$\Rightarrow$ John used the words: 'I don't'

In (9a), the elided VP in the second sentence is licensed by the first sentence, and one definitely does not infer that John's words involved an elided VP. The facts are different in (9b), which clearly attributes to John the use of the very words $I$ don't - hence a possible deviance if the context does not explain why John might have used a construction with ellipsis. When some information to this effect is added, the ellipsis within quotation marks becomes of course acceptable, as seen in (10b) (and it triggers an inference that the very words I don't were used by John).

(10) a. I just told John that you love Obama. He told me that he doesn't.

$\Rightarrow$ no inference about the precise words John used

b. I just told John that you love Obama. He told me: 'I don't.'

$\Rightarrow$ John used the words: 'I don't'

\subsubsection{Ellipsis under Attitude Role Shift in ASL}

Interestingly, ASL role-shifted clauses pattern with quoted sentences in English in terms of VP-ellipsis, as is seen in (11b) and (12b), which offer more controlled versions of $(9 b)$ and (10b) respectively. For completeness, we included in the paradigm some examples with the quotation operator " "; they pattern with Attitude Role 
Super monsters II

Shift. ${ }^{7}$ Acceptability ratings were lower, presumably for the same reason that (9b) above is somewhat deviant without a very special context; these ratings also turned out to be unstable, as seen in Appendix IV. More crucially, VP-ellipsis under Role Shift gave rise to quotational readings, which we established by way of an inferential task (Can one infer from these sentences which precise words John used? If so, which $\left.?^{8}\right)$.

(11) Context: John has never met the addressee.

a. 7 IX-2 LOVE OBAMA. JOHN

$\Rightarrow$ no inference about the precise words John used

'You love Obama. John tells me he doesn't.'

a'. 7 IX-2 LOVE OBAMA. JOHN a TELL-1 IX-a HATE OBAMA.

'You love Obama. John tells me he hates Obama.'

b. 4.5 IX-2 LOVE OBAMA. JOHN ${ }_{\mathrm{a}}$ TELL-1 $\frac{\mathrm{RS}_{\mathrm{a}}}{\mathrm{IX}-1 \mathrm{NOT}}$.

$\Rightarrow$ John used the (ASL) words: 'I don't'

'You love Obama. John tell me: 'I don't.'

b'. 6.7 IX-2 LOVE OBAMA. JOHN ${ }_{\mathrm{a}}$ TELL-1 $\frac{\mathrm{RS}_{\mathrm{a}}}{\mathrm{IX}-1 \text { HATE OBAMA. }}$

$\Rightarrow$ John used the (ASL) words: 'I hate Obama'

'You love Obama. John tells me: 'I hate Obama."

c. 4.7 IX-2 LOVE OBAMA. JOHN a TELL-1 “ " IX-1 NOT.

$\Rightarrow$ John used the (ASL) words: 'I don't'

'You love Obama. John tells me: 'I don't."

c'. 6.7 IX-2 LOVE OBAMA. JOHN a TELL-1 “ ” IX-1 HATE OBAMA.

$\Rightarrow$ John used the (ASL) words: 'I hate Obama'

'You love Obama. John tells me: 'I hate Obama."

(ASL, 14, 64)

Unsurprisingly, acceptability ratings improve markedly for (11b) and (11c) if the context makes it clear that the quoted construction with ellipsis had an antecedent in the reported conversation, as in (12); here too, an inferential task showed that Role Shift and the quotation operator genuinely gave rise to quotational readings (see Appendix IV).

7 As we mentioned in Part I, it cannot be excluded that the quotation operator introduces a non-standard variety of Role Shift (although one without body shift), in which case this observation is unsurprising. 8 We have more acceptability than inferential judgments because we had started with acceptability ratings only, and added inferential judgments later. The same remark holds for the corresponding LSF data in the next section. 
(12) Context: I am reporting on a conversation that Mary had with John.

a. 6.7 MARY $_{\mathrm{a}}$ FINISH TELL-b JOHN $\mathrm{b}_{\mathrm{b}}$ IX-a LOVE OBAMA. IX-b TELLa IX-b NOT.

'Mary told John that she loves Obama. He told her that he doesn't.'

a'. 7 MARY $_{\mathrm{a}}$ FINISH TELL-b JOHN IX-b HATE OBAMA.

'Mary told John that she loves Obama. He told her that he hates Obama.'

b. 6.7 MARY MINISH TELL-b JOHN $_{\mathrm{b}} \frac{\mathrm{RS}_{\mathrm{a}}}{\mathrm{IX}-1 \text { LOVE OBAMA. IX-b }}$

$\mathrm{RS}_{\mathrm{b}}$

TELL-a IX-1 NOT.

'Mary told John: 'I hate Obama.' He told her: 'I don't.'

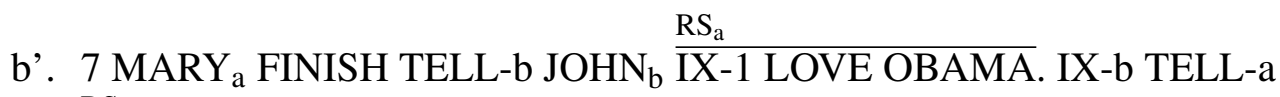
$\mathrm{RS}_{\mathrm{b}}$ IX-1 HATE OBAMA.

'Mary told John: 'I love Obama.' He told her: 'I hate Obama.'

c. 5 Mary $_{\mathrm{a}}$ FINISH TELL-b JOHN $\mathrm{b}$ “" IX-1 LOVE OBAMA. IX-b TELL-a “" IX-1 NOT.

'Mary told John: 'I love Obama.' He told her: 'I don't.'

c'. 5.7 Marya FINISH TELL-b JOHN TELL-a “" IX-1 HATE OBAMA.

'Mary told John: 'I love Obama.' He told her: 'I hate Obama.'

(ASL, 14, 68)

We conclude that ASL role-shifted clauses under attitude operators give rise to quotational readings.

\subsubsection{Ellipsis under Attitude Role Shift in LSF}

Similar conclusions can be obtained on the basis of LSF data: whenever Attitude Role Shift is used, an inference can be derived about the precise words that the agent used, and these must be the very words that appear in the role-shifted clause; no such effect arises without Role Shift. As was the case in some but not in all of our ASL data, the sentences were deemed acceptable even when the context failed to explain why a sentence with ellipsis could have been used in the reported dialogue; thus in this case inferential judgments are crucial to establish the existence of quotational readings. (We include for completeness data involving a quotation operator, which according to our consultant is reserved for important statements; for reasons we 
Super monsters II

don't understand, it led to lower acceptability than Role Shift with VP-ellipsis but no so much without it.)

(13) Context: The interlocutor and Sarkozy do not know each other. SARKOZY IX-2 a,2-THE-TWO DIFFERENT. IX-2 LIKE OBAMA. IX-a SAY

'You and Sarkozy are different. You like Obama. He says
a. $\quad$ 6.7 IX-a NOT-LIKE OBAMA. he doesn't like Obama.'$$
\mathrm{RS}_{\mathrm{a}}
$$
b. $7 \overline{\text { IX-1 NOT-LIKE OBAMA. }}$
'I don't like Obama."
c. $\quad 6.3$ “" IX-1 NOT-LIKE OBAMA.
'I don't like Obama."
(LSF, 25, 120)

(14) Context: The interlocutor and Sarkozy do not know each other.

SARKOZY IX-2 1,2-THE-TWO DIFFERENT. IX-2 LIKE OBAMA. SARKOZY / IX-a ${ }^{9}$ SAY

'You and Sarkozy are different. You like Obama. Sarkozy/he says
a. 7 IX-a NOT.
$\Rightarrow$ no inference about the precise words that Sarkozy used
he doesn't.'
b. 7 IX-1 NOT.
$\Rightarrow$ Sarkozy said 'I don't' ('moi non' in French)
'I don't."
c. 4 " "IX-1 NOT.
$\Rightarrow$ Sarkozy said 'I don't' ('moi non' in French)
'I don't."'
(LSF, 25, 122)

\subsubsection{Conclusion}

We conclude that in ASL and LSF Attitude Role Shift, if an elided VP appears in the role-shifted clause it cannot be licensed from outside that clause, and it is understood to be quoted from the situation which is reported. It should be noted that the ASL data present an interesting contrast between two kinds of gaps:

$9 \mathrm{SARKOZY}_{a}$ was used in (14a), IX- $a$ in (14b) and (14c). 
- As we saw in Part I, our consultant accepts $w h$-extraction out of a role-shifted clause, which suggests that a gap corresponding to a wh-trace escapes the quotational requirement.

- By contrast, the data we just saw suggest that an elided VP does not escape this quotational requirement.

In the end, then, the analysis will have to allow for fine-grained parameterization among constructions (and also among languages [or possibly consultants], since we saw that $w h$-extraction was dispreferred by our LSF consultant).

\subsection{Quotation of paralinguistic material}

Standard indirect discourse can have a quotational component, as is illustrated in (15). Here a phonological property of an embedded expression, the insertion of an extra phoneme in the word philosopher, is attributed to the attitude holder rather than to the speaker - a case of 'mixed quotation', but within a clause that has the hallmarks of indirect discourse (notably the complementizer that).

(15) My three-year old son believes that I am a 'philtosopher'. (Cappelen \& Lepore 1997)

Now within ASL, Attitude Role Shift differs from standard indirect discourse in that in such cases attribution to the attitude holder appears to be obligatory rather than optional. In other words, Attitude Role Shift appears to be interpreted as maximally quotational. We will establish this generalization on the basis of ASL data, and then we will extend it to LSF. We should note at the outset that this generalization need not be surprising from the perspective of sign language research: Attitude Role Shift is often treated as a kind of quotation, and the broader category of 'constructed action' is used to refer to cases in which the speaker in some way imitates properties of a reported speech act or action (see for instance Liddell \& Metzger 1998). In addition, the 'shifted attribution of expressive elements' under Role Shift has been described by several sign language researchers; see for instance Sandler \& Lillo-Martin 2006 (p. 382), who in turn cite Engberg-Pedersen 1993. ${ }^{10}$

\subsubsection{The quotational dimension of Attitude Role Shift in ASL}

In order to assess the quotational component of Role Shift, we asked our consultant to sign sentences in which the signer displays a happy face, something we encode as: $\therefore$-), followed by over the expressions that were accompanied by that happy

10 Engberg-Pedersen mentions in particular "the use of the signer's face and/or body posture to express the emotions or attitude of somebody other than the sender in the context of utterance". 
face. Importantly, this happy face is not a grammaticalized non-manual expression. We asked our consultant to start the happy face at the beginning of the report, in order to maximize the chance that this would be seen to reflect the signer's (rather than the agent's) happiness. In standard indirect discourse, this is indeed what we found, as shown in (16). In Attitude Role Shift, by contrast, the judgments in (17) suggest that it is more difficult to attribute the happy face to the signer only, despite the fact that it starts outside the role- shifted clause, and that the context is heavily biased to suggest that the agent of the reported attitude was anything but happy (note that the judgments varied over time, and that the contrasts were sharper in our initial trials; we do not know why this is so).

(16) SEE THAT(-a) ${ }^{11}$ ARROGANT FRENCH SWIMMER IX-a ${ }^{12}$ ? YESTERDAY IX-a ANGRY.

'See that arrogant French swimmer? Yesterday he was angry.

a. 7 IX-a SAY IX-a WILL LEAVE.

He said he would leave.'

b. 7 IX-a SAY IX-a WILL LEAVE.

Rating under the meaning: the SPEAKER is displaying his happiness that the French swimmer said he was leaving

He said he would leave.'

(ASL, 14, 231)

(17) SEE THAT-a ARROGANT FRENCH SWIMMER IX-a? YESTERDAY IX-a ANGRY.

'See that arrogant French swimmer? Yesterday he was angry.

a. 6.2 IX-a SAY IX-1 WILL LEAVE.

He said: 'I will leave."

$:-)$

b. $4.6^{13}$ IX-a SAY IX-1 WILL LEAVE

Rating under the reading: the SPEAKER is displaying his happiness that the French swimmer said he was leaving

11 Our consultant sees a clearly referenced locus in (16a) but not in (16b).

12 The signer hesitated before $I X-a$, and as a result it is not clear whether $I X-a$ belongs to the first or to the second sentence.

13 An additional task was performed by email (its results are discussed for Action Role Shift in fn. 16 and fn. 18). It included, among others, acceptability judgments without the imposition of a particular reading, and they are not incorporated in these averages. The scores obtained were: $(16 \mathrm{a})=7 ;(16 \mathrm{~b})$ $=7 ;(17 \mathrm{a})=7 ;(17 \mathrm{~b})=4$. 
He said: 'I will leave.'

(ASL, 14, 233)

\subsubsection{The quotational dimension of Attitude Role Shift in LSF}

Similar conclusions can be reached on the basis of LSF data: in the absence of Role Shift, the happy face is taken to reflect the speaker's rather than the agent's happiness, as seen in (18). By contrast, when Attitude Role Shift is applied, our consultant inferred that the happy expression reflected both the attitude of the speaker and that of the agent, as shown in (19). (Note that this both need not be very surprising, since the sentences were constructed in such a way that the happy face started at the beginning of the report rather than just on the role-shifted clause.) A methodological remark is in order, however: instead of asking our consultant to rate the sentence on a particular reading, as we did for ASL (with somewhat unstable results, as noted above), we asked for an inferential judgment (in French) pertaining to sentences with the happy face: Do we understand that the happy expression is that (i) of the speaker [ = <consultant's first name>]? (ii) of the arrogant German swimmer? Although the acceptability judgments were inconsistent (presumably because the sentence was grammatically acceptable but pragmatically odd), the inferential judgments were relatively stable.

(18) IX-2 IX-a [SWIMMER GERMAN $]_{\mathrm{a}}$ ARROGANT. YESTERDAY IX-a FURIOUS. ${ }^{14}$

'You see that arrogant German swimmer? Yesterday he was furious.

a. 7 IX-a SAY IX-a WILL LEAVE.

He said he would leave.'

b. 7 IX-a SAY IX-a WILL LEAVE

$\Rightarrow$ the happy face is the signer's (5 trials)

He said he would leave.'

(LSF, 25, 100)

IX-2 SEE IX-a [SWIMMER GERMAN] $]_{\mathrm{a}}$ ARROGANT. YESTERDAY IX-a FURIOUS. ${ }^{15}$

'You see that arrogant German swimmer? Yesterday he was furious.

14 For consistency, we compute averages over 4 sessions with our main consultant. Judgment from 1 session with another consultant are provided in Appendix IV.

15 For consistency, we compute averages over 4 sessions with our main consultant. Judgment from 1 session with another consultant are provided in Appendix IV. 
Super monsters II
a. 7 IX-a SAY
$\mathrm{RS}_{\mathrm{a}}$
He said: 'I will leave."
IX-1 WILL LEAVE.
$:-)$
b. 4 IX-a SAY IX-1 WILL LEAVE
$\Rightarrow$ the happy face is both the signer's and the German swimmer's (4 trials) or just the German swimmer's (1 trial)
He said: 'I will leave."

(LSF, 25, 102)

Thus there is a sharp difference between standard indirect discourse and Attitude Role Shift: in the latter, but not in the former, a happy face is preferably (or obligatorily) attributed to the agent of the reported speech act.

\subsubsection{Consequences}

We take these examples to show that, in a sense to be made precise below, expressions under Attitude Role Shift must be interpreted as being 'maximally quotational': non-grammatical material such as the 'happy face' used above must be attributed to the agent of the attitude under Attitude Role Shift, whereas this is not obligatory in standard indirect discourse.

Importantly, context-shifting theories cannot account for this fact without addition. The reason is that for a pure context-shifting theory, Attitude Role Shift differs from standard indirect discourse solely in the types of parameters that get shifted. To make things concrete, consider the two operators defined in (20a) and (20b) to analyze the Logical Forms in (21a) and (21b), the first of which involves Role Shift while the second involves standard indirect discourse (with a De Se reading). The Role Shift operator (written as $R S_{i}$ ) manipulates the context parameter and the world parameter, while the standard De Se operator (written as $O p_{i}$ ) manipulates the assignment function and the world parameter. Neither operator has the power to capture quotational effects, which would require that the right-hand side of (20a) and (20b) make reference to the form of the words used rather than just to their semantic values.

(20) For any clause $F$, context c, assignment function s and world w, and index i,

a. $\llbracket \mathrm{RS}_{\mathrm{i}} \mathrm{F} \rrbracket^{\mathrm{c}, \mathrm{s}, \mathrm{w}}=\lambda x_{e}^{\prime} \lambda w_{s}^{\prime} \cdot \llbracket \mathrm{F} \rrbracket^{\left\langle x^{\prime}, w^{\prime}\right\rangle, s, w^{\prime}}$

b. $\quad \llbracket \mathrm{Op}_{\mathrm{i}} \mathrm{F} \rrbracket^{\mathrm{c}, \mathrm{s}, \mathrm{w}}=\lambda x_{e}^{\prime} \lambda w_{s}^{\prime} \cdot \llbracket \mathrm{F} \rrbracket^{c, s\left[i \rightarrow x^{\prime}\right], w^{\prime}}$ 
Philippe Schlenker

(21) a. Role Shift

IX-a SAY RS a $_{\text {aX-1 WILL-LEAVE] }}$

b. No Role Shift, De Se Reading

IX-a SAY Op $p_{a}$ [IX-a WILL-LEAVE]

Two initial differences should be noted between our ASL data and the Zazaki data described in Anand 2006.

- As mentioned in Part I, in Zazaki NPIs that co-occur with shifted indexicals can be licensed from outside the relevant embedded clause.

- Anand 2006 argues that there is no general requirement that Zazaki clauses with shifted indexicals should be interpreted quotationally, as shown in (22a). (By contrast, he notes that English constructions that allow for partial quotation - confess in (22b) - force a reading on which the partially quoted expression was in fact used in the denoted situations). More research would be particularly useful on this topic; we will come back to this issue in Section 8.

(22) Anand (2006)

Fatima is enamored with Hesen, the brother of her friend Rojda, though Fatima thinks they are merely friends.

$\mathbf{S}_{\mathbf{1}}$ : One day, Fatima asks about Hesen, and Rojda tells her, "Hesen is very rich."

$\mathbf{S}_{\mathbf{2}}$ : Rojda tells her, "my brother Hesen is very rich."

a. Rojda va $\mathrm{kE}$ braya $\mathrm{mI}$ dewletia

Rojda say-PERF that brother I-EZ rich be

'Rojda $i$ said that her ${ }_{i}$ brother was rich.' $\left[\checkmark S_{1}, \checkmark S_{2}\right]$

b. Fatima continued to pester her for some detail about Hesen, and finally Rojda was forced to confess how rich 'my brother' was. [\# $S_{1}$, ? $S_{2}$ ]

\section{The Iconic Dimension of Action Role Shift in ASL and LSF}

Since Action Role Shift serves to report actions rather than attitudes, we do not expect it to have a quotational component. But we will see that in ASL and LSF alike, Action Role Shift comes with a requirement that it be interpreted 'maximally iconically', in a sense to be made precise below. A version of this requirement will turn out to suffice to explain the quotational component of Attitude Role Shift as well. Intuitively, iconic requirements have the effect that some geometric properties 
of signs are taken to 'resemble' properties of the situations referred to. Quotational effects can be seen as iconic effects of a particular sort: some expressions are taken to be identical to some elements of the situations described by the report. We will sketch in Section 4 a formal approach to iconic effects, one in which an expression is interpreted iconically if a structure-preserving map can be established between its form and certain properties of the situations of which it holds. In quotation, the map in question is just type-identity: the very words uttered in the report must be present in the denoted situation as well. We cannot expect to find such maps in the case of Action Role Shift, since the reported action usually does not involve words. But less stringent iconic requirements are in force in Action Role Shift; this is what we will now see with the example of the speaker's 'happy face'. Here too, our generalizations need not be surprising from the perspective of the sign language literature, since the very notion of 'constructed action' was developed to account for the fact that the signer may imitate some aspects of a scene he is attempting to describe (see for instance Liddell \& Metzger 1998 for a discussion framed in Mental Space Theory).

\subsection{Iconic effects with Action Role Shift in ASL}

Let us consider ASL first. In (23), which does not involve Role Shift, it is possible to understand the signer's happy face as reflecting the speaker's rather than the agent's attitude. Things are different in (24), where under Role Shift the signer's happy face is naturally taken to reflect the agent's attitude. Importantly, we do not claim that in the absence of Role Shift, this happy face cannot be attributed to the agent. This prediction would be too strong, and uncalled for: iconic effects are pervasive with or without Role Shift; our only claim is that under Action Role Shift, a happy face on the agent's part is normally attributed to the agent. ${ }^{16}$

16 Importantly, in a follow-up task conducted by email, we checked that (23b) and (24b) were both interpreted as action reports, and in particular that the latter did not give rise to an attitude reinterpretation (or at least not to an obligatory one). The results pertaining to (23b) and (24b) within that later task are reproduced in Appendix IV. Somewhat surprisingly, for (23b) the consultant took the happy expression to be attributed to the speaker; he added that it would be understood to be that of the French swimmer, 'but ANGRY prevents this typical interpretation'. (24b) did not contrast much in this respect; the consultant wrote that the happy face could be either assigned to the speaker or to the French swimmer, but that $A N G R Y$ conflicted with the latter interpretation. 
SEE THAT ARROGANT FRENCH SWIMMER IX-a? YESTERDAY IX-a ANGRY.

' See that arrogant French swimmer? Yesterday he was angry.

a. 7 IX-a a-WALK-WITH-ENERGY(CL-ONE) $)^{17}$

He left with energy.'

b. $\quad 6.2$ IX-a a-WALK-WITH-ENERGY(CL-ONE)

Rating under the meaning: the SPEAKER is displaying his happiness that the French swimmer was leaving

He left with energy.'

(ASL, 14, 231)

SEE THAT ARROGANT FRENCH SWIMMER IX-a? YESTERDAY IX-a ANGRY.

a. 7 IX-a $\frac{\mathrm{RS}_{\mathrm{a}}}{1-\mathrm{WALK}-\mathrm{WITH}-\mathrm{ENERGY(CL-ONE)} .}$

He left with energy.'

$$
\text { :-) }
$$

b. $\quad 3.6^{18}$ IX-a 1-WALK-WITH-ENERGY(CL-ONE).

Rating under the meaning: the SPEAKER is displaying his happiness that the French swimmer was leaving

He left with energy.'

(ASL, 14, 233)

While more work would be needed to establish these contrasts more securely (especially in view of the fact that iconic readings are certainly not prohibited in the absence of Role Shift), ${ }^{19}$ we take them to suggest that iconic material is preferably understood to reflect properties of the reported action under Role Shift.

$17 C L-O N E$ is used in parentheses to indicate that the construction involves the (moving) index finger classifier.

18 As mentioned in fn. 16, an additional judgment task was conducted by email, without imposition of particular readings; they are not incorporated to these averages. The ratings obtained were: $(23 \mathrm{a})=$ $7 ;(23 b)=4 ;$ and $(24 a)=(24 b)=2$.

19 We are cautious because in one paradigm (video 14, 235), sentences similar to (23)-(24) with the addition of WONDERFUL at the beginning of the third sentence gave rise to a null effect: the addition of the happy face (starting on WONDERFUL) gave rise to lower ratings both with and without Role Shift. We do not know why this is so. 
Super monsters II

\subsection{Iconic effects with Action Role Shift in LSF}

Our LSF data are complex. On the one hand, we replicate the effects we just saw in ASL: under Action Role Shift, a happy face must be attributed to the agent of the action rather than to the signer; in that sense, it seems that expressions under Role Shift must be interpreted 'maximally iconically'. On the other hand, there are surprising constraints on Action Role Shift, discussed in Part I, which might suggest that our LSF consultant obeys a stronger constraint, according to which every element that appears under Action Role Shift must have an iconic component.

We mentioned in Part I that it seems that Action Role Shift must be motivated by something - possibly by the existence of some iconic element in its scope. In the ASL example in (24a), the signer used a classifier construction to realize the embedded verb; specifically, the index finger classifier effected a movement in signing space, one which could be taken as a representation of the angry German swimmer moving in space. Our LSF consultant could not find a similar construction in this context, and therefore we constructed different examples, some of which worked under Action Role Shift and some of which didn't (we come back to this issue below). Focusing on one that did work, we found the result we expected on the basis of our ASL data:

- In action reports without Role Shift, the addition of a happy face starting before the Role Shift is acceptable and can be taken to reflect the speaker's rather than the agent's attitude, as seen in (25b).

- Under Action Role Shift, the addition of the happy face starting before the Role Shift leads to lower acceptability, and it tends to be taken to reflect (at least in part) the agent's attitude, as seen in (26b). This semantic fact might explain the lower ratings, as in the relevant sentences the agent is taken to be both happy and angry. ${ }^{20}$

(25) SEE IX-2 / IX-2 SEE ${ }^{21}$ [SWIMMER GERMAN $]_{(a)}^{22}$ ARROGANT. YESTERDAY IX-a FURIOUS.

'You see that arrogant German swimmer? Yesterday he was furious.

a. 7 FOR-THIS DOOR IX-a BREAK FALL.

That's why he broke open a door.'

20 Note that it is difficult to construct fully controlled paradigms: in principle, it could be that the lower ratings are due to the fact that the happy face was improperly realized in (26b) but not (26a). Controlling for this possibility would require more sophisticated methods.

21 SEE IX-2 was used in (25a), IX-2 SEE was used in (25b).

22 A slight orientation towards the right is visible in (25b) but not so much in (25a). 
Philippe Schlenker

b. 7 FOR-THIS DOOR IX-a BREAK FALL.

$\Rightarrow$ the happy expression is the speaker's (4 trials)

$\Rightarrow$ the arrogant German swimmer in fact broke the door (4 trials)

That's why he broke open a door.'

(LSF, 31, 230 23 )

(26)

IX-2 SEE [SWIMMER GERMAN] $]_{(\mathrm{a})}{ }^{24}$ ARROGANT. YESTERDAY IX-a FURIOUS.

'You see that arrogant German swimmer? Yesterday he was furious.

a. 7 (or 6$)^{25}$ FOR-THIS DOOR IX-a BREAK FALL.

That's why he broke open a door.'

:-)

b. 4.2 FOR-THIS DOOR IX-a BREAK FALL

$\Rightarrow$ the happy expression is both the speaker's and the arrogant swimmer's

(3 trials) / is the speaker's (1 trial)

$\Rightarrow$ the arrogant German swimmer in fact broke the door (4 trials)

That's why he broke open a door.'

(LSF, 31, 231 26 )

\subsection{Maximal Iconicity and Exhaustive Iconicity}

We conclude that Attitude and Action Role Shift both have an iconic component. Our generalization is tentatively stated in (27).

(27) Maximal Iconicity

In ASL and LSF Action Role Shift, expressions that can be interpreted iconically must be so interpreted.

23 A technical problem occurred when videos were transferred from the camera to the computer, with the result that video numbers got increased by 1 . As a result, judgment videos 31, 232 and 31, 233 [according to the final numbering] discuss 'video 229' (in lieu of video 230) and 'video 230' (instead of video 231). The necessary corrections have been made in this piece.

24 A slight orientation towards the right is visible in (26a) but not so much in (26b).

25 As seen in Appendix IV, in one trial the consultant noted that $I X-a$ was ambiguous and could be taken to refer to the addressee or to a third person; in the former case, the rating was 3, and in the latter a 7. Since the intended reading was a third person reading, we computed 7 in the 'official' average. An average of 6 is obtained if 3 instead of 7 is taken into account for that trial.

26 See fn. 23. 
We will develop the theory in two steps. First, in Section 4 we define a semantics in which iconic requirements can be integrated to an interpretation procedure. Second, in Section 5 we posit that the Role Shift operator comes with a (possibly pragmatic) requirement of maximal iconicity, and we show how this derives the main results we have seen.

Before we develop our analysis, it is worth pausing to revisit some LSF contrasts that remained mysterious in Part I. One pertained to the difference between the 'normal' verb $\mathrm{SHOW}$ and the classifier verb $\mathrm{SHOW}$-CL under (apparent) Action Role Shift: the former regularly triggered an attitude reinterpretation, whereas the latter didn't, as shown in (28) (repeated from Part I):

RECENTLY WOLF IPHONE FIND $_{c}$ HAPPY. SHEEP ${ }_{a}$ IX-b b-CALL-a. 'Recently the wolf was happy to find an iPhone. He called the sheep.

a. 4.3 IX-b IPHONE $\frac{\mathrm{RS}_{\mathrm{b}}}{1-\mathrm{SHOW}-\mathrm{a}}$. $\Rightarrow$ unclear inference

He [= the wolf] showed [or: said/thought he was showing/would show] the iPhone to him.'

b. 7 IX-b IPHONE $\frac{\mathrm{RS}_{\mathrm{b}}}{1-\mathrm{SHOW}-\mathrm{CL}-\mathrm{a}}$.

$\Rightarrow$ the wolf in fact showed the iPhone to the sheep

He [ $=$ the wolf] showed the iPhone to him.'

(LSF, 39, 26)

It was clear from our consultant's explanations that there is a semantic difference between the two verbs: $S H O W$ is compatible with many different ways in which the object could have been shown, whereas $S H O W-C L$ requires that the object be held with an open, $\mathrm{C}$-shaped hand - which is the very shape of verb itself, as shown by the picture in (28b). ${ }^{27}$ We thus make the following hypotheses:

- Hypothesis 1. The interpretation of $S H O W-C L$ has an iconic component, whereas that of SHOW doesn't.

27 In a session in which we explicitly asked our consultant to explain the difference between $S H O W$ and $S H O W$ - $C L$, he gave three examples for the former in the context of the wolf showing an iPhone he had just found: the action could be performed by pointing towards the iPhone, by holding it in one's mouth, or by holding it in one's hand; by contrast, only the latter possibility was open for SHOW-CL. (This result is important because the shape of the verb SHOW could in principle be taken to be iconic, as it involves a vertical, open non-dominant hand, with the dominant index pointing towards it; our consultant's intuitions suggest that it is not in fact interpreted iconically.) 
- Hypothesis 2. Under Attitude Role Shift, any word counts as being interpreted iconically if it has a quotational component (below, we will treat quotation as a special case of iconicity).

Now we hypothesize that our LSF consultant obeys the constraint in (29):

(29) Exhaustive Iconicity (LSF consultant; tentative)

In LSF, every word under Role Shift must have an iconically interpreted component.

For $S H O W-C L$, the condition in (29) is easily satisfied by virtue of Hypothesis 1 . For $S H O W$ this isn't the case, but an attitude reinterpretation does make it possible to satisfy the condition by virtue of Hypothesis 2 .

Let us see some possible consequences of Exhaustive Iconicity. In (30a), an attitude reinterpretation is triggered once again, and it targets both the noun and the verb that appear under Role Shift. In (30b), a more subtle phenomenon is found: as before, $S H O W-C L$ is interpreted as an action report, presumably because it has an iconic component that justifies its appearance under Role Shift. But IPHONE doesn't have such an iconic component, and thus gives rise to an attitude or quotational reinterpretation, with the mixed effect seen in the inferential judgments: the word IPHONE is taken to have been signed in the reported situation, but the action of showing it is understood to have been performed (rather than described).

RECENTLY WOLF IPHONE FIND HAPPY. SHEEP IX-b b-CALL-a.

'Recently the wolf was happy to find an iPhone. He called the sheep.

a. $\quad$ 6.7 IX-b $\frac{\mathrm{RS}_{\mathrm{b}}}{\mathrm{IPHONE} 1-\mathrm{SHOW}-\mathrm{a}}$.

$\Rightarrow$ the wolf said/thought he was showing/would show the iPhone to him

$\mathrm{He}$ [= the wolf] said/thought he would show/was showing the iPhone to him.'

$\mathrm{RS}_{\mathrm{b}}$

b. 7 IX-b IPHONE 1-SHOW-CL-a.

$\Rightarrow$ the wolf said 'iPhone' and showed the iPhone (see full ratings in Appendix IV)

He [= the wolf] said '(an) iPhone' and showed it.'

(LSF, 39, 37; see also LSF, 39, 27)

Still, not all nouns that appear under (apparent) Action Role Shift in LSF trigger an attitude reinterpretation: this doesn't seem to be the case in (31), where HOUSE DOOR BREAK FALL is compatible with an action reading. At this point, we can only hypothesize that the entire expression has an iconic component, as the verb $B R E A K$ targets the position determined by the sign DOOR, which is itself collocated with the sign HOUSE. 
Super monsters II

(31) IX-2 SEE SWIMMER GERMAN ARROGANT. YESTERDAY IX-a FURIOUS.

'You see that arrogant German swimmer? Yesterday he was furious.

6.5 FOR-THIS IX-a GO-BALLISTIC IX-a $\quad$ HOUSE DOOR BREAK FALL.

$\Rightarrow$ the arrogant German swimmer in fact broke the door

That's why he went ballistic and broke open the house door.'

(LSF, 36, 72; see also 35, 62; from Part I, (45a))

Be that as it may, more work is needed to determine whether there are independent grounds for thinking that this partly iconic interpretation is real, and whether it is indeed responsible for the action reading we obtain in this case. We leave this issue for future research.

\section{Iconic Interpretations}

In this section, we sketch a treatment of iconic effects, which will be crucial to our final analysis of Role Shift. In a nutshell, we follow Davidson 2015 in taking iconic enrichments to be effected by way of modification. ${ }^{28}$ In Davidson's analysis, this is implemented within an event semantics in which Role Shift has in essence the same contribution as the English expression like this, where this refers to very form of the role-shifted expressions. But since we wish to preserve the benefits of the intensional analysis of Role Shift in Part I, we frame the theory within a situation semantics instead (see Kratzer 2014 for a recent survey, and Elbourne 2005 for an analysis of anaphora with particularly fine-grained situations). Situations can be thought of as 'small worlds' (and we shall keep the mnemonic parameter w to refer to these 'small worlds', in order to maintain notational continuity with the possible worlds framework used in Part I). Only minor adjustments to our earlier formalism will be needed: we will reinterpret the world parameter as a 'small world'/situation parameter, with the assumption that situations are strictly more fine-grained than worlds (as a possible situation can be thought of as being part of a possible world); as a result, whatever can be done with worlds can be done with situations, since worlds can be thought of as situations of a particular kind (maximal ones; see for instance Kratzer 2014, Barwise 1988). ${ }^{29}$ On the other hand, we depart more

28 In an earlier version of this paper, we developed a different implementation, one in which some functor- argument structures gave rise to two function applications, once to the literal meaning of the argument, and once to its iconic meaning. This had some benefits in the analysis of Attitude Role Shift: a verb such as $S A Y$ was applied both to the propositional value of its argument, and to its quotational value. In effect, in such cases $X S A Y R S F$ ended up meaning that $\mathrm{X}$ says that $\mathrm{F}$ and $\mathrm{X}$ says: $F$. But this analysis was complex; we hope that the present version is simpler, and also makes it easier to compare our theory with Davidson's. 
essentially from Davidson's analysis in assuming that in Attitude and Action Role Shift alike, expressions have both their normal meaning and an iconic contribution. By contrast, Davidson develops a dual analysis in which Attitude Role Shift is an instance of pure quotation/demonstration, whereas in Action Role Shift expressions are both used and demonstrated (a more detailed comparison is developed in Section 7).

\title{
4.1 Introduction: GROW
}

What do we mean by 'iconic effects'? To see an intuitively clear example, consider the verb GROW in (32), which can be realized in a variety of ways, six of which were tested in (33).

\author{
POSS-1GROUP GROW. \\ 'My group has been growing.' (8, 263; 264) (Schlenker et al. 2013)
}

\section{Three remarks should be added.}

1. To see why situations are needed, take the example of $X S A Y S$, with a quotationally/iconically interpreted embedded clause $S$. We wish to say that this sentence is true in a situation w just in case (i) in w, X said that $\mathrm{S}$, and (ii) this was effected with the very words that appear in $S$. In our analysis, we can posit that the form of $S$ played a role in the situation w. As long as situations are 'small' and fine-grained enough, this is a non-trivial constraint. If we dealt with worlds instead, the specification would be insufficiently informative, as particular sentences may play a role in all sorts of parts of a world without necessarily appearing in the relevant speech situation.

2. In the formal implementation of Part I, we took contexts to be basically pairs of the form $\langle$ individual, world $\rangle$. Nothing is lost when worlds are made more fine-grained: a context can then be identified with a pair of the form 〈individual, situation (of thought/speech) $\rangle$. (We also have the further option of taking contexts to just be primitive situations of a particular sort, rather than pairs of the form 〈individual, situation〉 - but this further option would require adjustments to the formal analysis of Part I).

3. As an alternative framework, one could be tempted to replace our worlds of evaluation with contexts of evaluation rather than situations of evaluation in order to obtain sufficiently finegrained parameters. On this view, in the interpretation function $\llbracket . \rrbracket^{\mathrm{c}, \mathrm{s}, \mathrm{w}}$, both $\mathrm{c}$ and $\mathrm{w}$ are contexts. But pairs of the form 〈individual, world $\rangle$ would be insufficiently fine-grained for that purpose (in our example $X S A Y S$, we would need to posit that the form of $S$ be plays a role in a pair of the form 〈individual, world > - but intuitively the form of $S$ plays a role in an event or a situation, which is more fine-grained). In addition, using contexts (qua thought/speech situations) to play the role of worlds of evaluation raises questions about intensional constructions that are not attitudinal. For instance, there is no reason a modal or an if-clause should solely quantify over situations of thought or speech, whereas it does make sense to have them quantify over a variety of possible situations (but see von Stechow \& Zimmermann 2005 for a system with contexts replacing worlds).

30 The beginning of this section borrows from Schlenker et al. 2013 and Schlenker 2014. 
Super monsters II

(33)

Representation of GROW

\begin{tabular}{|l|l|l|l|}
\hline & Narrow endpoints & Medium endpoints & Broad endpoints \\
\hline Slow movement & small amount, slowly & medium amount, slowly & large amoun, slowly \\
& & \\
\hline
\end{tabular}

The sign for GROW in (32) starts out with the two hands forming a sphere, with the closed fist of the right hand inside the hemisphere formed by the left hand; the two hemispheres then move away from each other on a horizontal plane (simultaneously, the configuration of the right hand changes from closed to open position). The signer varied two main parameters in (33): the distance between the endpoints; and the speed with which they were reached. ${ }^{31}$ All variants were entirely acceptable, but yielded different meanings, as shown in (33). Intuitively, there is a mapping between the physical properties of the sign and the event denoted: the broader the endpoints, the larger the final size of the group; the more rapid the movement, the quicker the growth process.

To handle this case, we will assume that the context of utterance c makes available a relation of similarity between some signs and their denotations. An example is given in (35). In (35a), GROW appears without a superscript and thus gets its normal interpretation, taking as argument $M Y G R O U P$, which we take to denote a certain group group $\mathrm{g}(\mathrm{w})$ in situation w. In (35b), $G R O W^{k}$ carries an iconic index $k$, and as a consequence its normal interpretation is enriched with an iconic requirement to the effect that the amount and speed of the growth correspond to those represented by the sign. The key to that enrichment is a condition $\operatorname{sim}_{c, w}\left(g r o w ', G R O W^{k}, g\right)$ which requires that in the situation of evaluation $w$, a similarity relation given by the context $\mathrm{c}$ should hold between the property of growing as applied to $\mathrm{g}$ and the iconically interpreted sign $G R O W^{k}{ }^{32}$

31 The paradigm was not fully minimal, in the sense that further aspects of the sign tended to be modified as well.

32 Two technical remarks should be added. 
Philippe Schlenker

\section{(34) Notational conventions}

a. We write $\llbracket \mathrm{F} \rrbracket^{c, s}$ for $\lambda w_{s} . \llbracket \mathrm{F} \rrbracket^{c, s, w}$, where $w$ is the world/situation parameter, of type s (written as a subscript on the variable binder in cases of potential ambiguity).

b. We write as word' the lexical meaning of a sign language expression $W O R D$ - thus grow' is used in the meta-language to refer to the meaning of the sign language word GROW.

(35) Let $\mathrm{c}$ be a context, $\mathrm{s}$ an assignment function, and $\mathrm{w}$ a situation, and assume that $\llbracket$ MY GROUP $\rrbracket^{\mathrm{c}, \mathrm{s}, \mathrm{w}}=g(w)$.

We assume that the normal and the iconic meaning of GROW are total functions.

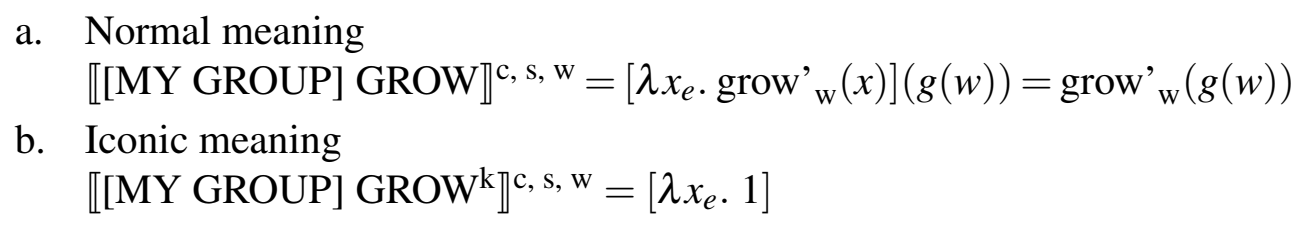

It remains to explain what it means for the function grow' to be similar to the token $G R O W^{k}$. We can think of $\operatorname{sim}_{c, w}$ (grow', GROW', $g$ ) as meaning that the property of growing applied to object $\mathrm{g}(\mathrm{w})$ in situation $\mathrm{w}$ is similar to the token $G R O W^{k}$ along dimensions that are specified by the context c. A possible example of a specification is given in (36); it implements the requirement that if something grows in the situation of evaluation, it grows by an amount and at a speed that are compatible with the iconic specifications of the verb. (Combined with the assertion that something grows in the situation of evaluation, this will yield the (at-issue)

(i) The specification 'as applied to g' is needed because we will have to distinguish among iconic enrichments of 'centered propositions' of type $\langle\mathrm{e},\langle\mathrm{s}, \mathrm{t}\rangle\rangle$ depending on their functor or argument status. As an example, consider a role-shifted clause with a happy face, for instance :-) [RS $\Omega_{a} \varnothing_{1}$ 1-WALK-WITH-ENERGY]. In Attitude Role Shift, this clause appears as the argument of a verb, for instance SAY, and an iconic index (more specifically, a quotational index) will impose that this proposition be expressed (by the agent) using the very words and expressions that appear in the clause. By contrast, the iconic enrichment of the same clause appearing as a functor with a subject argument (for instance $I X-a$ ) in Action Role Shift will be different: it will impose in the end that the action of walking in the situation of evaluation involved a smile. It is thus important that $\operatorname{sim}_{c, w}$ can distinguish between different enrichments of the role-shifted clause depending on whether it serves as a functor or as an argument. We come back to this point in fn. 37.

(ii) In quantified cases (e.g. in sentences meaning a group grew, every group grew, etc.), we assume that a trace (of type e) will replace the subject, and relative to an assignment function the derivation will proceed as in this case. 
Super monsters II

meaning that something grows by an amount and at a speed determined by the iconic specifications of the verb, as is desired.)

(36) We assume that the context of utterance c makes salient an 'amount' function $\mathrm{am}_{\mathrm{c}}$ and a 'speed' function $\mathrm{sp}_{\mathrm{c}}$, used as follows:

a. For every situation $\mathrm{w}$, iconic index $\mathrm{k}$, and individual concept $\mathrm{t}^{33} \mathrm{~g}$ (of type $\langle\mathrm{s}, \mathrm{e}\rangle), \operatorname{sim}_{\mathrm{c}, \mathrm{w}}\left(\right.$ grow' $\left.^{\prime}, \mathrm{GROW}^{\mathrm{k}}, \mathrm{g}\right)=1$ iff if $\operatorname{grow}_{\mathrm{w}}(\mathrm{g}(\mathrm{w}))=1$, then in $\mathbf{w}$

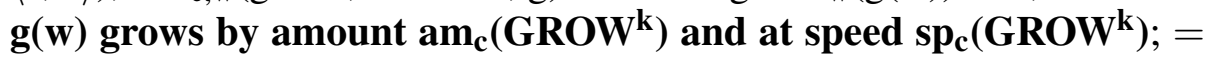
0 otherwise.

b. Preservation requirements on the functions $\mathrm{am}_{\mathrm{c}}$ and $\mathrm{sp}_{\mathrm{c}}$

(i) If the endpoints of $\mathrm{GROW}^{\mathrm{k}}$ are more distant than the endpoints of GROW $^{\mathrm{i}}, \operatorname{am}_{\mathrm{c}}\left(\mathrm{GROW}^{\mathrm{k}}\right)>\mathrm{am}_{\mathrm{c}}\left(\mathrm{GROW}^{\mathrm{i}}\right)$.

(ii) If the speed of GROW ${ }^{k}$ is greater than the speed of GROW ${ }^{i}, \operatorname{sp}_{c}\left(G R O W^{k}\right)$ $>\operatorname{sp}_{\mathrm{c}}\left(\mathrm{GROW}^{\mathrm{i}}\right)$.

We can simplify the truth conditions in (35b) by replacing $\operatorname{sim}_{c, w}\left(g r o w ', G R O W^{k}, g\right)$ with the boldfaced condition in (36):

$\llbracket[$ MY GROUP $]$ GROW $\rrbracket^{\mathrm{c}, \mathrm{s}, \mathrm{w}}=1$ iff $\operatorname{grow}_{\mathrm{w}}(\mathrm{g}(\mathrm{w}))=1$ and $\operatorname{sim}_{\mathrm{c}, \mathrm{w}}($ grow', $\left.\mathrm{GROW}^{\mathrm{k}}, \mathrm{g}\right)=1 ; 0$ otherwise

$=1$ iff grow' ${ }_{\mathrm{w}}(\mathrm{g}(\mathrm{w}))=1$ and, in $\mathrm{w}, \mathrm{g}(\mathrm{w})$ grows by amount $\operatorname{am}_{\mathrm{c}}\left(\mathrm{GROW}^{\mathrm{k}}\right)$ and at speed $\mathrm{sp}_{\mathrm{c}}\left(\mathrm{GROW}^{\mathrm{k}}\right) ; 0$ otherwise

The final effect is to ensure that the particular realization of the sign GROW provides information about the amount and speed of the growth - as is desired.

It remains to say under what conditions a sentence is true. Here a minor adjustment of the framework of Part I is needed, since we now take the world parameter to be a situation parameter instead. In a standard intensional framework, one would say that a sentence $S$ uttered in a context c is true just in case $S$ evaluated at the context $\mathrm{c}$ and in the world of $\mathrm{c}$ is true. With a situation rather than a world parameter, one should posit instead that $S$ is true just in case for some situation $w$ (in a certain domain) in the world of c, $S$ evaluated at context c and in situation w is true. We have 'built in' this existential quantification in the definition of truth in (38), and we have taken it to be restricted to situations the sentence is 'about', sometimes called 'topic situations' in the literature (see Kratzer 2014 for a survey; an alternative would have been to add to the Logical Form of the sentence a restricted existential quantifier

33 Within the present framework, it is natural to use 'individual concept' in an extended sense, to refer to functions from situations to individuals (rather than to functions from worlds to individuals, as is standard). 
Philippe Schlenker

over situations, but for present purposes we prefer to keep Logical Forms as simple as possible). ${ }^{34}$

\section{(38) Definition of truth}

If $S$ is a sentence uttered in a context c, if the assertion of $S$ is intended to hold in a domain of situations $\mathrm{D}_{\mathrm{c}}$ in the world of $\mathrm{c}$, and if the assignment function s properly represents the referential intentions of the speaker of $\mathrm{c}$, $S$ yields a failure if and only if for some situation $w$ in $D_{c}, \llbracket S \rrbracket^{\mathrm{c}, \mathrm{s}, \mathrm{w}}=\#$. Otherwise, $S$ is true if and only if for some situation $w$ in $D_{c}, \llbracket S \rrbracket^{\mathrm{c}, \mathrm{s}, \mathrm{w}}=1$.

Applied to (37), this definition yields the desired results, as seen in (39).

(39) $\left[M Y\right.$ GROUP] GROW $W^{k}$ is true in context $\mathrm{c}$ iff there is a situation $\mathrm{w}$ in the intended domain $\mathrm{D}_{\mathrm{c}}$ such that grow' ${ }_{\mathrm{w}}(\mathrm{g}(\mathrm{w}))=1$ and, in $\mathrm{w}, \mathrm{g}(\mathrm{w})$ grows by amount $\mathrm{am}_{\mathrm{c}}\left(\mathrm{GROW}^{\mathrm{k}}\right)$ and at speed $\mathrm{sp}_{\mathrm{c}}\left(\mathrm{GROW}^{\mathrm{k}}\right)$; otherwise [MY GROUP] $G R O W^{k}$ is false.

In the rest of this piece, we will not attempt to be precise about the specification of the 'similarity' relation, except for the case of quotational indices, analyzed as a special and particularly stringent case of iconic enrichment.

Importantly, in at least some cases iconic enrichments are at-issue, and can take scope under logical operators. This is shown by the ASL example in (40)-(41), where iconic size and speed modifications enrich the meaning of GROW within the scope of the if-clause.

(40) 7 IF GROUP GROW_little , IX-1 LEAD IX-1. IF GROW_medium , IX-a MARY LEAD. IF GROW_large, IX-b JOHN LEAD.

'If my group grows a little bit, I'll be the one leading it. If it grows a decent amount, Mary will; if it grows a lot, John will.' (ASL, 23, 71)

7 IF GROUP GROW_slow_incremental, IX-1 LEAD IX-1. IF GROW_medium , IX-a MARY LEAD. IF GROW_fast, IX-b JOHN LEAD.

'If my group grows slowly, I'll lead it; if it grows at a normal rate, Mary will; if it grows fast, John will.' $(23,75)$

34 There are two reasons for taking the existential quantification to be contextually restricted. First, existential claims over situations rarely range over all the situations in the world of the context: It rained means something more precise than there is some situation in the world in which it rained: a situation close to the situation of utterance is usually intended. Second, and more theory-internally, we follow Heim 1983 in taking statements with existential force to project presuppositions universally, hence we would get absurd results if the sentence resulted in a failure as soon as it has the value \# in at least one situation in the entire world. As an example, It stopped raining would incorrectly presuppose that it rained in the entire world of the context — an undesirable result. (Thanks to D. Beaver for spotting an error in an earlier formulation.) 
Super monsters II

Due to these observations, as well as for reasons of simplicity, we will mostly treat iconic enrichments as being at-issue ${ }^{35}$ (but see Schlenker et al. 2013 and Schlenker 2014 for iconic contributions that are presuppositional when they pertain to the denotation of loci).

\subsection{Formal Treatment}

\subsubsection{Goals}

As announced, we will posit that role-shifted expressions must be interpreted in a maximally iconic fashion. Our formal analysis has two main goals.

- First, we want predicates such as GROW-fast to be iconically enriched in such a way that the relevant property as instantiated in the situation of evaluation is similar in relevant respects to the sign itself.

- Second, we wish to explain why Attitude Role Shift yields pervasive quotational effects. For reasons mentioned in Part I (pertaining to wh-extraction facts in ASL, and to our goal of giving a unified analysis of Attitude and Action Role Shift), we need to posit that in Attitude Role Shift the embedded clause is both used and mentioned. We achieve this result by positing that in these cases the 'similarity' relation introduced above on the example of GROW requires that the proposition involved in the situation of evaluation should be realized by the very form of the embedded clause. At this point, it would not make much sense to have such a requirement hold of a world of evaluation. On the other hand, making this demand of a 'small world' or situation involving a speech act does make sense, which is why we reinterpret the world parameter of Part I as a situation parameter. (The latter plays an analogous role to Davidson's events. Events and situations are usually thought to have a slightly different structure, since for instance events but not necessarily situations are associated with thematic roles. Our analysis could be extended in such an event-theoretic direction if needed, but at the cost of making the connection with the intensional framework of Part I a bit less transparent.)

On the syntactic side, we will start from a base language L generated by a grammar $\mathrm{G}$, and assume that we can obtain an enriched grammar $\mathrm{G}^{+}$which can generate an iconically enriched language $\mathrm{L}^{+}$, with derivation trees in which some constituents carry iconic indices — as is discussed in greater detail in Appendix B. On the semantic side, we wish to guarantee that some functors and some arguments

35 We write 'mostly' because quotational indices will have some presuppositional requirements as well. 
can be iconically enriched, since both the case of the functor GROW and of the propositional argument of $S A Y$ must be covered. As announced, we follow Davidson 2015 in taking iconic enrichment to be effected by way of modification, but we do so within a situation-theoretic semantics in which our world parameter (used in Part I) is re-analyzed as a situation parameter. This will make it possible to analyze iconic enrichments in Action Role Shift, but also to explain why in Attitude Role Shift the role-shifted clause is both used and mentioned, as desired (we compare our analysis to Davidson 2015 in Section 7).

Importantly, we do not seek to explain why some expressions have a greater iconic potential than others (e.g. in LSF SHOW-CL in (28b) can be interpreted iconically, whereas $S H O W$ in (28a) apparently cannot be). In the present analysis, such differences may be captured by taking the similarity function provided by the context to yield a failure when it takes as arguments expressions that do not have the right iconic potential (the intuition is that such expressions have a shape that is not conducive to iconic enrichments).

\subsubsection{Enriched syntax}

For simplicity, we assume that the base language L is produced by a Phrase Structure Grammar with unary or binary branching, and in which constituents can be annotated with semantic types. We enrich it to a language $\mathrm{L}^{+}$in which iconic indices appear on the following types of constituents in binary-branching derivation trees:

(i) sister-to-sister configurations of the form $E^{i} F^{j}, E^{i} F, E F^{j}$ for $i, j \in \mathbb{N}$, where $E$ or $\mathrm{F}$ has a type $\langle\mathrm{a}, \mathrm{b}\rangle$ that 'ends in $\mathrm{t}^{36}$, and its sister has type a;

(ii) constituents of the form $E^{i}$, where $E$ is of type t.

For reasons we will come to shortly, iconic indices will only be interpreted as semantic composition takes place and involves a constituent of a conjoinable type, hence the restrictions in (i). Expressions of type $t$ are in effect ones that take the world/situation parameter as an argument, and thus they can be iconically enriched-hence the addition in (ii).

Appendix B defines a procedure that delivers constituent structures such as (42), which corresponds to the example discussed in (35b) and illustrates case (i) above (= GROW is of type $\langle\mathrm{e}, \mathrm{t}\rangle$, and takes an argument of type e); and also (43b) where

36 See for instance Rooth \& Partee 1982. The definition of types 'that end in t' (= 'conjoinable types') can be given as in (i):

(i) a. t is a conjoinable type

$\mathrm{b}$. If $\mathrm{b}$ is a conjoinable type, then for any type $\mathrm{a},\langle\mathrm{a}, \mathrm{b}\rangle$ is a conjoinable type. 
a happy face appears on an entire clause - which illustrates case (ii) (= the entire clause, of type $t$, is iconically enriched). Note that the iconic index that appears on an expression singles out a particular realization ( $=$ a token $)$ of a type, and hence $G R O W^{k}$ corresponds to a particular iconic realization of the verb, while the entire expression [[MY GROUP] GROW $]^{k}$ also corresponds to a particular realization of the entire clause - in the case of interest here, one involving a happy face (this is the reason we informally include the happy face in (43a), but we take the index k to include the relevant information in the Logical Form represented in (43b)).

[MY GROUP] GROWk
a. $\frac{:-)}{[[M Y ~ G R O U P] ~ G R O W]}$
b. [[MY GROUP] GROW $]^{\mathrm{k}}$

\subsubsection{Enriched semantics}

On the semantic side, we start from a base interpretation $\llbracket . \rrbracket^{\mathrm{c}, \mathrm{s}, \mathrm{w}}$ (relativized to a context parameter $\mathrm{c}$, an assignment function $\mathrm{s}$, and a situation parameter $\mathrm{w}$ [rather than a world parameter as in Part I]), and we add to it a syncategorematic rule designed to interpret iconic indices.

By construction of the syntax, we only need to specify the mechanism of semantic enrichment when a functor whose type 'ends in t' is applied to an argument (including the case in which the functor is of type $t$ and takes an implicit situation argument). The restriction to these types is important because the iconic enrichment is itself propositional (as it states that some aspects of a situation are 'similar' to a token of a sign), and it must thus be conjoined with a propositional meaning.

As in our example above involving $G R O W$, we make crucial use of a relation $\operatorname{sim}_{c, w}$, as shown in the interpretive rules in (44). If $E$ is of type t, $\operatorname{sim}_{c, w}\left(\llbracket E \rrbracket^{c, s}, E^{i}\right)$ is intended to mean that in the situation $\mathrm{w}$ what realizes the proposition $\llbracket E \rrbracket^{c, s}$ is in relevant respects similar to the expression $E^{i}$. The intuition is that if the proposition $\llbracket E \rrbracket^{c, s}$ plays a role in the situation w, it does so by way of something in that situation - for instance a sentence uttered in w. And one can require that that thing - in our example, the relevant sentence uttered in $\mathrm{w}$ - should be similar to the form of $E^{i}$. If $E$ or $F$ is of another type that 'ends in t', $\operatorname{sim}_{c, w}\left(\llbracket E \rrbracket^{c, s}, E^{i}, \llbracket F \rrbracket^{c, s}\right)$ is intended to mean that in the situation $\mathrm{w}$ what realizes $\llbracket E \rrbracket^{c, s}$ (qua functor or argument, as the case may be depending on $\llbracket F \rrbracket^{c, s}$ ) is in relevant respects similar to the expression $E^{i}$. Thus if $\llbracket E \rrbracket^{c, s}$ plays the role of a functor and corresponds to a verbal denotation, e.g. $\llbracket G R O W \rrbracket^{c, s}$, it may play a role in w because an a certain action of the appropriate type, e.g. a growth, occurs in w; and one can require that action be similar in relevant 
respects to expression $E^{i}$ - in our example, to a particular iconic realization of a sign. Thus in each case, what realizes a denotation $\llbracket E \rrbracket^{c, s}$ of an expression $E$ in the situation of evaluation $w$ is required to be relevantly similar to the form of $E .{ }^{37}$ Still, it is not our goal in this paper to give a general theory of 'similarity', and we will be content to provide plausible constraints on a case-by-case basis. ${ }^{38}$

\section{(44) Syntactegorematic interpretation of iconic indices}

Let $i$ and $k$ be two iconic indices, and let $E^{i}$ and $F^{k}$ be two expressions of the language $\mathrm{L}^{+}$. They should be interpreted in accordance with Rule 1, or if inapplicable with Rule 2.

Rule 1. If $E$ is of type t,

$\llbracket E^{i} \rrbracket^{c, s, w}=\#$ iff $\llbracket E \rrbracket^{c, s, w}$ or $\operatorname{sim}_{c, w}\left(\llbracket E \rrbracket^{c, s}, E^{i}\right)=\# ;=1$ iff $\llbracket E \rrbracket^{c, s, w}=$ $\operatorname{sim}_{\mathrm{c}, \mathrm{w}}\left(\llbracket \mathrm{E} \rrbracket^{\mathrm{c}, \mathrm{s}}, \mathrm{E}^{\mathrm{i}}\right)=1$

Rule 2. If $E$ is of a type that 'ends in t' and needs $\mathrm{n}$ arguments of types $\tau_{1}$, $\ldots, \tau_{\mathrm{n}}$ (in that order) to yield a truth value, if $F$ is of type $\tau_{1}$, and if $\mathrm{x}_{2}, \ldots, \mathrm{x}_{\mathrm{n}}$ are (meta-language) variables of types $\tau_{2}, \ldots, \tau_{\mathrm{n}}$ respectively, then:

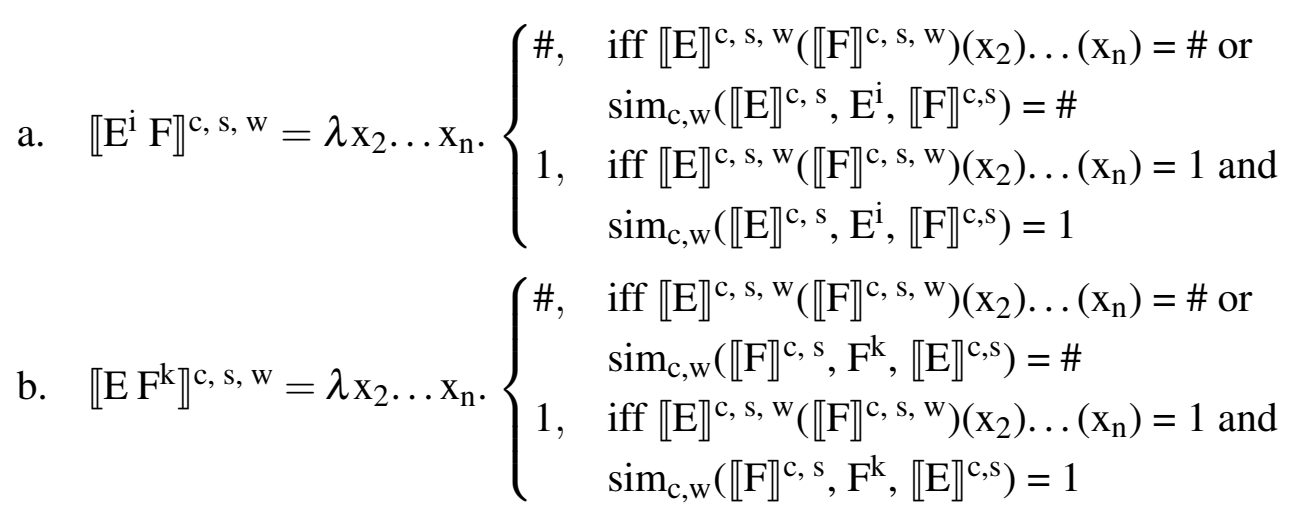

37 As anticipated in fn. 32, we take $\operatorname{sim}_{c, w}$ to take as input information both about $\llbracket E \rrbracket^{c, s}$ and about $\llbracket F \rrbracket^{c, s}$ because we wish to allow it to treat one and the same expression differently depending on whether it is a functor or an argument. Concretely, a role-shifted clause such as $R S_{a} \varnothing_{1} \quad$ 1-WALKWITH-ENERGY could appear either as an argument of SAY (in a case of Attitude Role Shift), or as a functor taking a subject - e.g. IX- $a$ - as argument (in a case of Action Role Shift). In the first case, the role-shifted clause can be given a quotational index, and the semantics will require that the very form of that sentence play a role in the situation of evaluation; such a quotational interpretation would make no sense in the second case (we make use of the latter fact in the assessment of the condition of 'maximal iconicity' at the very end of Section 5.2).

38 In this respect, our theory is underspecified in the same general way as that of Davidson 2015. Her iconically enriched Logical Forms include an event modifier tantamount to the expression like this, where this makes reference to the form of a particular expression. This is implemented by way of a primitive relation of the form demonstration $(d, e)$, where $e$ is an event and $d$ is a gestural component of a sign. This notion is as underspecified as our notion of similarity. In Davidson's terms: "demonstration $(\mathrm{d}, \mathrm{e})$ holds $(\ldots)$ if $\mathrm{d}$ reproduces properties of e and those properties are relevant in the context of speech". See Section 7 for a more detailed comparison between our theory and Davidson's. 
Super monsters II

c. $\llbracket \mathrm{E}^{\mathrm{i}} \mathrm{F}^{\mathrm{k}} \rrbracket^{\mathrm{c}, \mathrm{s}, \mathrm{w}}=\lambda \mathrm{x}_{2} \ldots \mathrm{x}_{\mathrm{n}} \cdot \begin{cases}\#, & \text { iff } \llbracket \mathrm{E} \rrbracket^{\mathrm{c}, \mathrm{s}, \mathrm{w}}\left(\llbracket \mathrm{F} \rrbracket^{\mathrm{c}, \mathrm{s}, \mathrm{w}}\right)\left(\mathrm{x}_{2}\right) \ldots\left(\mathrm{x}_{\mathrm{n}}\right)=\# \text { or } \\ & \operatorname{sim}_{\mathrm{c}, \mathrm{w}}\left(\llbracket \mathrm{E} \rrbracket^{\mathrm{c}, \mathrm{s}}, \mathrm{E}^{\mathrm{i}}, \llbracket \mathrm{F} \rrbracket^{\mathrm{c}, \mathrm{s}}\right)=\# \text { or } \\ & \operatorname{sim}_{\mathrm{c}, \mathrm{w}}\left(\llbracket \mathrm{F} \rrbracket^{\mathrm{c}, \mathrm{s}}, \mathrm{F}^{\mathrm{k}}, \llbracket \mathrm{E} \rrbracket^{\mathrm{c}, \mathrm{s}}\right)=\# \\ 1, & \text { iff } \llbracket \mathrm{E} \rrbracket^{\mathrm{c}, \mathrm{s}, \mathrm{w}}\left(\llbracket \mathrm{F} \rrbracket^{\mathrm{c}, \mathrm{s}, \mathrm{w}}\right)\left(\mathrm{x}_{2}\right) \ldots\left(\mathrm{x}_{\mathrm{n}}\right)=1 \text { and } \\ & \operatorname{sim}_{\mathrm{c}, \mathrm{w}}\left(\llbracket \mathrm{E} \rrbracket^{\mathrm{c}, \mathrm{s}}, \mathrm{E}^{\mathrm{i}}, \llbracket \mathrm{F} \rrbracket^{\mathrm{c}, \mathrm{s}}\right)=1 \text { and } \\ & \operatorname{sim}_{\mathrm{c}, \mathrm{w}}\left(\llbracket \mathrm{F} \rrbracket^{\mathrm{c}, \mathrm{s}}, \mathrm{F}^{\mathrm{k}}, \llbracket \mathrm{E} \rrbracket^{\mathrm{c}, \mathrm{s}}\right)=1\end{cases}$

To illustrate, consider again the derivation tree in (42), repeated as (45a); it can be interpreted as in (45b). Here we make reference once again to the iconic enrichment of GROW discussed in (36), whereby the speed with which the sign is realized reflects the speed of the growth, and the distance between the endpoints of the sign reflects the degree of the growth.

a. [MY GROUP] GROW ${ }^{\mathrm{k}}$

b. Let $\mathrm{c}$ be a context, $\mathrm{s}$ an assignment function and $\mathrm{w}$ a situation. We assume that $\llbracket \mathrm{POSS}-1$ GROUP $\rrbracket^{\mathrm{c}, \mathrm{s}, \mathrm{w}}=\mathrm{g}(\mathrm{w})$, and that rrow $^{\prime}{ }_{w}(g(w))$ and $\operatorname{sim}_{c, w}\left(\right.$ grow' $\left.^{\prime}, G R O W^{k}, g\right)$ take classical values. Then:

[[POSS-1 GROUP] GROW ${ }^{\mathrm{k}} \rrbracket^{\mathrm{c}, \mathrm{s}, \mathrm{w}}$

$=\left[\lambda \mathrm{x}_{\mathrm{e}} .1\right.$ iff $\llbracket$ GROW $\rrbracket^{\mathrm{c}, \mathrm{s}, \mathrm{w}}(\mathrm{x})=\operatorname{sim}_{\mathrm{c}, \mathrm{w}}\left(\right.$ grow' $\left.^{\prime}, \mathrm{GROW}^{\mathrm{k}}, \mathrm{g}\right)=1 ; 0$ otherwise $](\mathrm{g}(\mathrm{w}))$

$=1$ iff grow' ${ }_{\mathrm{w}}(\mathrm{g}(\mathrm{w}))=\operatorname{sim}_{\mathrm{c}, \mathrm{w}}\left(\right.$ grow' $\left.^{\prime}, \mathrm{GROW}^{\mathrm{k}}, \mathrm{g}\right)=1 ;=0$ otherwise (by $\lambda$-conversion)

$=1$ iff grow' ${ }_{\mathrm{w}}(\mathrm{g}(\mathrm{w}))=1$ and in $\mathrm{w} \mathrm{g}(\mathrm{w})$ grows by amount $\mathrm{am}_{\mathrm{c}}\left(\mathrm{GROW}^{\mathrm{k}}\right)$ and at speed $\mathrm{sp}_{\mathrm{c}}\left(\mathrm{GROW}^{\mathrm{k}}\right) ; 0$ otherwise (by (36))

Suppose that the iconic component to be interpreted is a happy face on the entire clause, as in (46a). We take this to correspond to an iconic index $k$ that appears on the matrix node, and we apply Rule 1 of (44).

a. $\frac{:-)}{[[\mathrm{MY} \text { GROUP] GROW] }}$

a'. [[MY GROUP] GROW $]^{\mathrm{k}}$

b. Let $\mathrm{c}$ be a context, $\mathrm{s}$ an assignment function and $\mathrm{w}$ a situation. We assume that $\llbracket$ POSS-1 GROUP $\rrbracket^{\mathrm{c}, \mathrm{s}, \mathrm{w}}=\mathrm{g}(\mathrm{w})$, and that $\operatorname{grow}^{\prime}{ }_{w}(g(w))$ and $\operatorname{sim}_{c, w}\left(\right.$ grow', $^{\prime}$ GROW $\left.^{k}\right)$ take classical values.

$\llbracket\left(46 \mathrm{a}^{\prime}\right) \rrbracket^{\mathrm{c}, \mathrm{s}, \mathrm{w}}=1$ iff grow' $_{\mathrm{w}}(\mathrm{g})=1$ and $\operatorname{sim}_{\mathrm{c}, \mathrm{w}}\left(\lambda \mathrm{w}^{\prime}\right.$ grow $^{\prime}{ }_{\mathrm{w}}{ }^{\prime}\left(\mathrm{g}\left(\mathrm{w}^{\prime}\right)\right)$, $\left.\left(46 \mathrm{a}^{\prime}\right)\right)=1 ; 0$ otherwise

It remains to specify what the iconic component of (46b) is. We propose the relation in (47), which has the effect of enriching the literal meaning of MY GROUP GROW with the information that the speaker is happy about this fact, as shown in (48). The 
similarity function imposes the requirement that if the speaker's group grows in the situational of evaluation, the speaker is happy of this fact. Combined with the assertion that the speaker's group does grow in that situation, this yields the meaning that the group grows and the speaker is happy of this. Different specifications of the similarity relation could of course be proposed depending on the context, and we leave an exploration of such alternatives (as well as necessary constraints on them) for future research.

$\operatorname{sim}_{\mathrm{c}, \mathrm{w}}\left(\lambda \mathrm{w}^{\prime}\right.$ grow' $\left._{\mathrm{w}}\left(\mathrm{g}\left(\mathrm{w}^{\prime}\right)\right),\left(46 \mathrm{a}^{\prime}\right)\right)=1$ iff if grow' ${ }_{\mathrm{w}}(\mathrm{g}(\mathrm{w}))=1$, then in $\mathrm{w}$ the speaker of $\mathrm{c}$ is happy that $\lambda \mathrm{w}^{\prime} \mathrm{grow}_{\mathrm{w}}{ }^{\prime}\left(\mathrm{g}\left(\mathrm{w}^{\prime}\right)\right)$; 0 otherwise.

$\llbracket(46 a) \rrbracket^{\mathrm{c}, \mathrm{s}, \mathrm{w}}=1$ iff grow' ${ }_{\mathrm{w}}(\mathrm{g}(\mathrm{w}))=1$ and in $\mathrm{w}$ the speaker of $\mathrm{c}$ is happy that $\lambda w^{\prime}$ grow' $_{w^{\prime}}\left(g\left(w^{\prime}\right)\right) ; 0$ otherwise.

\subsection{Quotation as iconicity}

We will now argue that quotational effects can be obtained as a special case of iconicity. An example will make this clear, but to appreciate it we should first consider a case of Attitude Role Shift without quotation. The definitions in (50)(52) are borrowed from Part I, except that we have replaced the word world with situation. ${ }^{39}$ As in Part I, the analysis is based on a standard De Se semantics with context shift: an individual $\mathrm{x}$ believes that $\mathrm{p}$ in situation $\mathrm{w}$ just in case for every individual $\mathrm{x}$ ' and situation $\mathrm{w}$ ' compatible with what $\mathrm{x}$ believes in $\mathrm{w}$, the centered proposition $\mathrm{p}$ is true of $\mathrm{x}^{\prime}, \mathrm{w}^{\prime}$. Since contexts are just pairs of the form $\left\langle\mathrm{x}^{\prime}, \mathrm{w}^{\prime}\right\rangle$, the analysis can just as well be stated by quantifying over contexts c' compatible with what $\mathrm{x}$ believes in $\mathrm{w}$, and recovering from each such context c' the agent of c', notated as $c^{\prime}$, and the situation of the context, notated as $\mathrm{c}^{\prime}{ }_{\mathrm{w}}$. Thus $\mathrm{x}$ believes that $\mathrm{p}$ in situation $w$ just in case for every context c' compatible with what $x$ believes in $\mathrm{w}, \mathrm{p}$ is true of $\mathrm{c}^{\prime}{ }_{\mathrm{a}}, \mathrm{c}^{\prime}{ }_{\mathrm{w}}$. Similarly, $\mathrm{x}$ says that $\mathrm{p}$ is true in situation $\mathrm{w}$ just in case for every context c' compatible with what $x$ claims in $w ', p$ is true of c' ${ }_{a}, c^{\prime}{ }_{w}$.

As in Part I, the analysis is developed by defining contexts as in (49), and the semantics of role-shifted clauses as in (50).

\section{Contexts}

a. Let $\mathrm{D}$ be a set of individuals and let $\mathrm{W}$ be a set of possible worlds. The set of contexts is $\mathrm{C}=\mathrm{D} \times \mathrm{W}$.

39 Since our system makes no provisions for tense, we obtain highly simplified truth conditions. In particular, applying the definition of truth in (38) to (54), we get a meaning akin to: in some situation, a says that he is leaving, with a doubly De Se reading (with respect to the agent and situation argument of leaving). We would need an embedded quantifier over situations to obtain other readings for the embedded clause. 
Super monsters II

b. Notation: if $\mathrm{c} \in \mathrm{C}$ with $\mathrm{c}=\langle\mathrm{x}, \mathrm{w}\rangle$, we write the author coordinate of $\mathrm{c}$ as $\mathrm{c}_{\mathrm{a}}(=\mathrm{x})$ and its world coordinate as $\mathrm{c}_{\mathrm{w}}(=\mathrm{w})$.

(50) Semantics of role shifted-clauses $\frac{R S_{i}}{I P}$, written as $R S_{i} I P$

Let $\mathrm{c}$ be a context, $\mathrm{s}$ an assignment function and $\mathrm{w}$ a situation. Then for any index $i$ and clause $I P$,

$\llbracket R S_{i} I P \rrbracket^{c, s, w}=\lambda x^{\prime}{ }_{e} \lambda w^{\prime}{ }_{s} \cdot \llbracket I P \rrbracket^{\left\langle x^{\prime}, w^{\prime}\right\rangle, s, w^{\prime}}$

To illustrate, we apply this definition to the role-shifted clause $R S_{a}$ [IX-1 WILLLEAVE]:

$\llbracket \mathrm{RS}_{\mathrm{a}}[\mathrm{IX}-1$ WILL-LEAVE $] \rrbracket^{\mathrm{c}, \mathrm{s}, \mathrm{w}}=\lambda \mathrm{x}_{\mathrm{e}}{ }_{\mathrm{e}} \lambda \mathrm{w}^{\prime}{ }_{\mathrm{s}} \cdot \llbracket$ IX -1 WILL-LEAVE $\rrbracket^{\left\langle\mathrm{x}^{\prime}, \mathrm{w}^{\prime}\right\rangle, \mathrm{s}, \mathrm{w}}$ $=\lambda \mathrm{x}_{\mathrm{e}} \lambda \mathrm{w}^{\prime}{ }_{\mathrm{s}}$. will-leave' ${ }_{\mathrm{w}}{ }^{\prime}\left(\mathrm{x}^{\prime}\right)$

Our semantics for $S A Y$ is also borrowed from Part I, with situations replacing possible worlds: ${ }^{40}$

(52) Modified definition of the semantics of $S A Y$

Let $\mathrm{SAY}_{\mathrm{w}}(\mathrm{x})$ be the set of contexts compatible with what an individual $\mathrm{x}$ says in situation $\mathrm{w}$.

For any object $\mathrm{p}$ of type $\langle\mathrm{e},\langle\mathrm{s}, \mathrm{t}\rangle\rangle$ (where $\mathrm{s}$ is the type of situations), for any object $\mathrm{x}$ of type e, for any context $\mathrm{c}$, assignment function $\mathrm{s}$ and situation $\mathrm{w}$, $\llbracket \mathrm{SAY} \rrbracket^{\mathrm{c}, \mathrm{s}, \mathrm{w}}(\mathrm{p})(\mathrm{x})=\#$ iff for some $\mathrm{c}^{\prime} \in \mathrm{SAY}_{\mathrm{w}}(\mathrm{x}), \mathrm{p}\left(\mathrm{c}^{\prime}{ }_{\mathrm{a}}\right)\left(\mathrm{c}^{\prime}{ }_{\mathrm{w}}\right)=\#$. If $\neq \#$, $\llbracket S A Y \rrbracket^{c, s, w}(p)(x)=1$ iff for every $c^{\prime} \in \operatorname{SAY}_{w}(x), p\left(c^{\prime}{ }_{a}\right)\left(c^{\prime}{ }_{w}\right)=1$.

Using the results of (51), we can derive the truth conditions of an entire attitude report involving a role-shifted clause, as shown in (53)-(54).
$\mathrm{RS}_{\mathrm{a}}$
a. IX-a SAY IX-1 WILL LEAVE
b. IX-a SAY RS $\mathrm{a}_{\mathrm{a}}[\mathrm{IX}-1$ WILL-LEAVE]

$$
\begin{aligned}
& \llbracket(53 b) \rrbracket^{c, s, w} \\
& =\llbracket S A Y \rrbracket^{c, s, w}\left(\llbracket R S_{a}[I X-1 \text { WILL-LEAVE }] \rrbracket^{c, s, w}\right)\left(\llbracket I X-a \rrbracket^{c, s, w}\right)
\end{aligned}
$$

40 It may be useful to remind the reader that the standard De Se/context-shifting semantics does not force the author of the contexts compatible with the relevant attitude (written as $c^{\prime}$ in (52)) to be identical to the attitude holder (written as $x$ in (52)). This is by design: as Lewis 1979, Chierchia 1987 and Schlenker 2003 emphasized, if John is wrong about who he is (for instance because he is an amnesiac, or delusional), the contexts compatible with his beliefs are ones whose agent may not be John. As a result, the De Se attitude report John hopes to be elected will assert something about contexts whose author is not John — and this remark would extend to other attitudes, as well as to constructions with shifted indexicals. In more standard situations in which John is not an amnesiac or delusional, the contexts compatible with his attitude have John himself as an author; but this is identity is enforced by world knowledge, not by the semantics. 
$=\llbracket \mathrm{SAY} \rrbracket^{\mathrm{c}, \mathrm{s}, \mathrm{w}}\left(\lambda \mathrm{x}^{\prime}{ }_{\mathrm{e}} \lambda \mathrm{w}^{\prime}{ }_{\mathrm{s}}\right.$. will-leave' $\left.{ }_{\mathrm{w}}{ }^{\prime}\left(\mathrm{x}^{\prime}\right)\right)(\mathrm{s}(\mathrm{a})) \neq \# ;=1$ iff for every c' $\in$

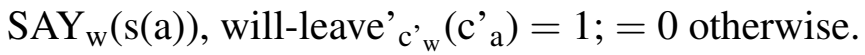

Going one step further, we will now suggest that the quotational effect of Attitude Role Shift can be obtained as a special case of iconicity. We introduce distinguished indices which we call 'quotational indices', and which correspond to special specifications of the similarity function $\mathrm{sim}$. For practical purposes, we use 0 as a quotational index. The basic idea is that when the role-shifted clause carries a quotational index, the denotation of the embedded clause must be expressed in the situation of evaluation by the very words that appear in that clause. Importantly for what follows, we posit a failure if a quotational index appears on an expression that is not used as a propositional argument (whether it is a 'normal' proposition of type $\langle\mathrm{s}, \mathrm{t}\rangle$, or a 'centered' proposition of type $\langle\mathrm{e},\langle\mathrm{s}, \mathrm{t}\rangle\rangle)$.

(55) If 0 is a quotational index, if $F^{0}$ and $E$ are expressions of $\mathrm{L}^{+}$, $\operatorname{sim}_{\mathrm{c}, \mathrm{w}}\left(\llbracket \mathrm{F} \rrbracket^{\mathrm{c}, \mathrm{s}}, \mathrm{F}^{0}, \llbracket \mathrm{E} \rrbracket^{\mathrm{c}, \mathrm{s}}\right)=\#$ unless $\llbracket \mathrm{F} \rrbracket^{\mathrm{c}, \mathrm{s}, \mathrm{w}}$ is of ('normal' or 'centered') propositional type $(\langle\mathrm{s}, \mathrm{t}\rangle$ or $\langle\mathrm{e},\langle\mathrm{s}, \mathrm{t}\rangle\rangle)$ and $\llbracket \mathbf{F} \rrbracket^{\mathrm{c}, \mathrm{s}, \mathbf{w}}$ can be an argument of $\llbracket \mathbf{E} \rrbracket^{\mathbf{c}, \mathbf{s}, \mathbf{w}}$;

if $\neq \#,=1$ iff $\llbracket \mathrm{F} \rrbracket^{\mathrm{c}, \mathrm{s}}$ is expressed in $\mathrm{w}$ by the string $F .{ }^{41}$

We can now see the effects of this iconic enrichment when it is combined with the rules we specified in (44). Specifically, since the propositional argument of $S A Y$ is iconically enriched, we must apply Rule $2 b$ (for legibility we abbreviated the role-shifted clause as $R$ when its denotation appears as an argument of $\operatorname{sim}_{\mathrm{c}, \mathrm{w}}$ ).
a. IX-a SAY [RS ${ }_{\mathrm{a}}[\mathrm{IX}-1 \text { WILL-LEAVE] }]^{0}$
with $\mathrm{R}=\left[\mathrm{RS}_{\mathrm{a}}[\mathrm{IX}-1\right.$ WILL-LEAVE $\left.]\right]$
b. $\llbracket(56 a) \rrbracket$ c, s, w
$=\llbracket$ SAY $\left[\mathrm{RS}_{\mathrm{a}}[\mathrm{IX}-1 \text { WILL-LEAVE }]\right]^{0} \rrbracket^{\mathrm{c}, \mathrm{s}, \mathrm{w}}\left(\llbracket \mathrm{IX}-\mathrm{a} \rrbracket^{\mathrm{c}, \mathrm{s}, \mathrm{w}}\right)$
$=\left[\lambda \mathrm{x}_{\mathrm{e}}{ }_{\mathrm{e}} .1\right.$ iff $\llbracket \mathrm{SAY} \rrbracket^{\mathrm{c}, \mathrm{s}, \mathrm{w}}\left(\llbracket \mathrm{RS}_{\mathrm{a}}\right.$ [IX-1 WILL-LEAVE $\left.] \rrbracket^{\mathrm{c}, \mathrm{s}, \mathrm{w}}\right)(\mathrm{x})=1$ and $\operatorname{sim}_{\mathrm{c}, \mathrm{w}}\left(\llbracket \mathrm{R} \rrbracket^{\mathrm{c}, \mathrm{s}}, \mathrm{R}^{0}, \llbracket \mathrm{SAY} \rrbracket^{\mathrm{c}, \mathrm{s}}\right)=1 ; 0$ otherwise $](\mathrm{s}(\mathrm{a}))$
(since the expressions involved do not contain presupposition triggers, and no presupposition failure is triggered for type reasons);
$=1$ iff for every $\mathrm{c}^{\prime} \in \mathrm{SAY}_{\mathrm{w}}(\mathrm{s}(\mathrm{a}))$, will-leave' ${ }_{\mathrm{c}^{\prime}}{ }_{\mathrm{w}}\left(\mathrm{c}^{\prime}{ }_{\mathrm{a}}\right)=1$ and $\llbracket \mathrm{R} \rrbracket^{\mathrm{c}, \mathrm{s}}$ is

41 This could be made more precise, for instance as in (i):

(i) $\ldots=1$ iff if for arguments $x_{1}, \ldots, x_{n}$ of the appropriate type, $\llbracket E \rrbracket^{c, s, w}\left(\llbracket F \rrbracket^{c, s, w}\right)\left(x_{1}\right) \ldots\left(x_{n}\right)=$ 1 , then in $\mathrm{w}_{1}, \ldots, \mathrm{x}_{\mathrm{n}}$ stand in a relation corresponding to $\llbracket \mathrm{E} \rrbracket^{\mathrm{c}, \mathrm{s}, \mathrm{w}}$ (e.g. the relation of saying) to the string $F$.

Within an event-theoretic semantics, one could modify the analysis to ensure that a sentence such as $x$ says $S^{0}$ (with a quotational index on $S$ ) is true just in case there is an event e such that e is a saying, the agent of $\mathrm{e}$ is the denotation $\mathrm{x}$, the theme of $\mathrm{e}$ is the denotation of $S$, and in e the theme of e is expressed by the string $S$. We come back to this point at the end of Section 5.4, and in Section 7. 
Super monsters II

expressed in w by $R^{0} ; 0$ otherwise.

Paraphrasing: (a) is true just in case every context compatible with what the agent says makes true I will leave, and the embedded proposition is expressed by these very words (in ASL).

In the end, we see that the role-shifted expression is both used and mentioned - it has its standard meaning (as affected by a context-shifting operator), but it also comes with a condition to the effect that in the situation of evaluation the meaning of that proposition is expressed by the very words that appear in the embedded clause.

At this point, it must be noted that what we have formally treated as a Role Shift operator is in fact realized as a rotation of the signer's body, and thus that a quotational analysis of the entire role-shifted clause provides a plausible reading, one whereby the reported speaker just used the words IX-1 WILL-LEAVE signed from a different position than the signer's normal one (if $R S_{a}$ were realized as an operator, we would attribute to the reported agent the use of this operator, which would be incorrect).

\subsection{Comparison with theories of quotation}

Our account shares an important feature with several analyses of quotation which posit that certain expressions can be both used and mentioned.

As Recanati $(2001,2008)$ emphasized, it was traditionally thought that all quotations are 'closed', in the sense that they are singular terms denoting certain strings of words, as in (57).
a. 'It is raining' contains three words.
b. And then Greta Garbo said 'I want to be alone'. (Recanati 2001, (3))

In contrast to this tradition, Recanati argues that there are many cases in which quotations do not function as singular terms, but rather are used as 'open quotations', in which "words are ostensively displayed, but their syntactic and semantic type remains unaffected", and hence where "the quotation is not grammatically recruited as a singular term" (Recanati 2008 p. 443); this is illustrated in (58).

(58) 'I am fed up with all this'. Don't you have any thing more constructive to say? (Recanati 2008, (3))

Following Clark \& Gerrig 1990, Recanati argues that quotations can both be used and have an iconic component. ${ }^{42}$ We reach similar conclusions on the basis of different

42 In Recanati's terms (2001 p. 681), "what the demonstration conveys in virtue of its pictorial meaning can be incorporated into the utterance's truth-conditional content — or at least, into the content of the speaker's assertion - through the process of pragmatic enrichment". 
data. Action Role Shift makes it almost necessary to develop an analysis in which expressions can be used and have an iconic component simultaneously. But once a theory has been developed for Action Role Shift, the analysis of Attitude Role Shift can be made to follow as a special case, and it becomes entirely natural to posit that in that environment expressions are both used and quoted.

Turning to more recent approaches, a major contender in recent theories of mixed quotation is the presuppositional approach, according to which the mixed quotation in (59a) is given, as a first approximation, a meaning akin to (59b) (here we follow the discussion in Maier 2014a).

(59) a. Quine said that quotation 'has a certain anomalous feature'.

b. Quine said that quotation has what he referred to as 'a certain anomalous feature'.

This line of analysis has several advantages. First, it immediately explains why expressions under mixed quotation appear to be both used and mentioned, since the truth conditions make reference both to the denotation of the expression and to its form. Second, it also explains why it is not normally part of the at-issue content that the expression was quoted (rather, this is presupposed). As emphasized by Maier 2014a, although one can reply to (59a) with (60), it is in this case presupposed that the expression 'a certain anomalous feature' was used in prior discourse, and what is negated is that quotation has the property denoted by this expression. This is adequately predicted by analyses along the lines of (59b), since the expression what $x$ referred to as 'a certain anomalous feature' presupposes that $\mathrm{x}$ used the relevant expression to refer to some property.

(60) Nonsense, quotation is not "anomalous" - it's very natural and ubiquitous.

Third, Maier 2014a and Geurts \& Maier 2005 argue that various possibilities of accommodation are exemplified for presupposition and partial quotation alike - for instance, in Tony didn't call the "POlice" (he called the "poLICE"), the information that the term POlice was used takes scope under negation and can be explained in terms of 'local accommodation' of a presupposition.

While one could treat Role Shift as a signal that the role-shifted expressions are partially quoted, and thus simultaneously used and mentioned, there are two obstacles to this extension. First, and most importantly, Action Role Shift does not involve quotation, and it is because we are aiming for a (relatively) unified theory of Action and Attitude Role Shift that we appeal to the broader notion of iconicity. Second, and more narrowly, we have no evidence that the constructions we have studied here are presupposition triggers; in fact, the data we discussed in (40)-(41) suggest that some instances of iconic enrichment can take scope under if-clauses, 
and yield no evidence of projection. Thus the precise connection between Role Shift and partial quotation will have to be investigated further in the future. ${ }^{43}$

\section{Role Shift and Maximal Iconicity in ASL}

We will now propose that in Attitude and Action Role Shift alike, the role-shifted clause comes with a requirement that it should be interpreted 'maximally iconically'. The basic idea is sketched in Section 5.1; it is applied to Action Role Shift in Section 5.2 and to Attitude Role Shift in Section 5.3. At this point, we only seek to derive the ASL data. Necessary refinements for LSF are discussed in Section 6. For simplicity, the discussion starts from the simpler framework of Part I, in which no distinction was drawn among indexicals that can vs. cannot appear in Action Role Shift (we come back to this point at the end of this section).

\subsection{Basic Idea}

We start by defining the conditions under which a clause $S$ is interpreted 'maximally iconically'. In brief, this happens if it is impossible to 'add' iconic indices or to turn

43 As it stands, our account does not capture cases of partial quotation in (59) and (60). In fact, our quotational indices can only be added to full propositional arguments, as specified in (55) (this, in turn, is important for our statement of 'iconicity maximization' under Role Shift, as we will see in Section 5: we wish to explain why iconic indices are mandatory in Attitude Role Shift but not in Action Role Shift; in the latter, quotational indices would trigger a presupposition failure). As a result, a Logical Form such as (i) would yield a semantic failure.

(i) Quine says that quotation [is-anomalous $]^{0}$

Still, we could relax the constraints in (55). However this would not deliver the right truth conditions. Assuming that no semantic failure arises, we could obtain for the embedded clause in (i) the truth conditions in (ii), possibly specified further thanks to (iii).

(ii) $\llbracket$ quotation is-anomalous $\rrbracket^{\mathrm{c}, \mathrm{s}, \mathrm{w}}=1$ iff $\llbracket$ anomalous $\rrbracket^{\mathrm{c}, \mathrm{s}, \mathrm{w}}\left(\llbracket\right.$ quotation $\left.\rrbracket^{\mathrm{c}, \mathrm{s}, \mathrm{w}}\right)=$ $\operatorname{sim}_{\mathrm{c}, \mathrm{w}}\left(\llbracket\right.$ anomalous $\rrbracket^{\mathrm{c}, \mathrm{s}}$, anomalous ${ }^{0}, \llbracket$ quotation $\left.\rrbracket^{\mathrm{c}, \mathrm{s}}\right)=1 ;=0$ otherwise

$=1$ iff anomalous' ${ }_{\mathrm{w}}($ quotation' $)=\operatorname{sim}_{\mathrm{c}, \mathrm{s}}\left(\right.$ anomalous', anomalous ${ }^{0}$, quotation' $^{\prime}=1 ;=0$ otherwise.

(iii) $\operatorname{sim}_{\mathrm{c}, \mathrm{w}}$ (anomalous', anomalous ${ }^{0}$, quotation') $=1$ iff in w the property of being anomalous (i.e. anomalous') is referred to with the word 'anomalous'.

But the difficulty is that the entire embedded clause is in an intensional context, and thus we would end up attributing to Quine a claim that the property of being anomalous is expressed by the word 'anomalous'. Arguably we want something different, namely that in fact part of Quine's claim was expressed by the word 'anomalous'. We might be able to derive this result if we allow the situation argument of $\operatorname{sim}_{c, w}$ (anomalous', anomalous ${ }^{0}$, quotation') to be set to the situation of the context rather than to the situation of evaluation - and thus to 'escape' the semantic scope of the attitude verb. We leave this question for future research. 
existing ones into quotational indices without triggering a presupposition failure. For technical reasons that will become clear in Section 5.3, we need to assume that a quotational index is 'more iconic' than a normal iconic index; this makes some conceptual sense, as a quotational interpretation forces identity between the relevant expression and an element of the situations referred to - whereas standard iconic interpretation just requires the existence of a appropriate mapping between them.

(61) Maximal Iconicity

A clause $S$ is interpreted maximally iconically relative to a syntactic environment $a \_b,{ }^{44}$ a context c, an assignment function s and a situation w just in case

(i) $a S b$ interpreted relative to c, s, w does not give rise to a failure; AND

(ii) it is impossible to

a. add iconic superscripts on expressions of $S$ that are not already contained within an iconically interpreted constituent within $S$, or to

b. turn some iconic superscripts on expressions of $S$ that are not already contained within an iconically interpreted constituent within $S$ into quotational indices, so as to obtain a 'more iconic' expression $\mathrm{S}^{+}$such that $\mathrm{aS}^{+} \mathrm{b}$ does not yield a failure relative to $\mathrm{c}, \mathrm{s}$ and $\mathrm{w}$.

We then take the Role Shift operator to introduce a requirement according to which its sister is interpreted maximally iconically. This revised interpretive rule is stated below:

\section{Maximal Iconicity of Role Shift}

$R S_{i} I P$ is only acceptable relative to a syntactic environment $a \_b$, a context c, an assignment function $\mathrm{s}$ and a situation $\mathrm{w}$ if $R S_{i} I P$ is interpreted maximally iconically relative to $a \_b, \mathrm{c}, \mathrm{s}$ and $\mathrm{w}$.

We will now illustrate the workings of the system for Action and then for Attitude Role Shift.

\subsection{Action Role Shift}

Let us consider the derivation of the truth conditions of a simple sentence involving Action Role Shift, as in (63a), analyzed as in (63b).

44 The definition makes reference to a syntactic environment because failure conditions for the target clause may depend on its interaction with operators and lexical material that appear in the rest of the sentence. Hence one must take into account this broader syntactic environment to determine whether a clause is indeed interpreted in a maximally iconic fashion. 
Super monsters II
$\mathrm{RS}_{\mathrm{a}}$
a. IX-a 1-WALK-WITH-ENERGY(CL-ONE).
'He left with energy.'
b. [w* ${ }^{*} \mathrm{IX}-\mathrm{i}-\overline{\mathrm{RS}} \mathrm{R}_{\mathrm{a}} \varnothing_{1} 1$-WALK-WITH-ENERGY]
In this example, a happy face appears on the entire role-shifted expression. Since the Role Shift operator triggers abstraction over individuals and situations (as specified in (50)), the role-shifted expression ends up being of type $\langle\mathrm{e},\langle\mathrm{s}, \mathrm{t}\rangle\rangle$, and it must thus take an individual argument (here: $I X-a$ ) and a world argument (here: $w^{*}$ ) to yield a truth value. Thus we can use Rule 2a in (44) to interpret the result:

(64) Let $\mathrm{E}^{1}=\left[\frac{-\overline{\mathrm{RS}} \mathrm{a} \varnothing_{1} 1 \text {-WALK-WITH-ENERGY }}{1}\right]^{1}$. For any context $\mathrm{c}$, assignment function $\mathrm{s}$ and situation $\mathrm{w}$, $\llbracket(63 b) \rrbracket^{\mathrm{c}, \mathrm{s}, \mathrm{w}}=$

$$
\begin{aligned}
& \llbracket \mathrm{w}^{*} \mathrm{IX}-\mathrm{a}\left[\overline{\mathrm{RS}_{\mathrm{a}} \varnothing_{1} 1-\mathrm{WALK}-\mathrm{WITH}-\mathrm{ENERGY}}\right]^{1} \rrbracket^{\mathrm{c}, \mathrm{s}, \mathrm{w}} \\
& =\llbracket \mathrm{IX}-\mathrm{a} \mathrm{E}^{1} \rrbracket^{\mathrm{c}, \mathrm{s}, \mathrm{w}}(\mathrm{w})
\end{aligned}
$$

by Rule $2 \mathrm{a}$ in (44),

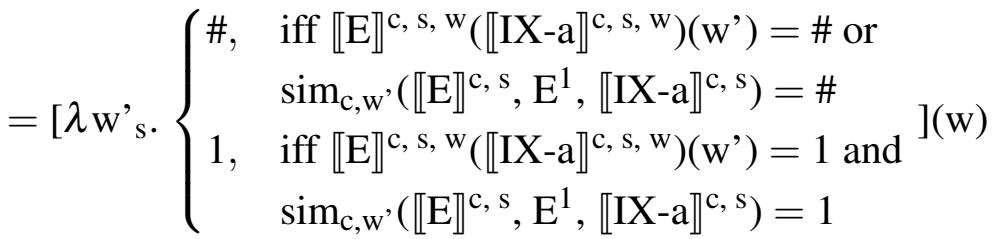

$$
\begin{aligned}
& = \begin{cases}\#, & \text { iff } \llbracket \mathrm{E} \rrbracket^{\mathrm{c}, \mathrm{s}, \mathrm{w}}\left(\llbracket \mathrm{IX}-\mathrm{a} \rrbracket^{\mathrm{c}, \mathrm{s}, \mathrm{w}}\right)(\mathrm{w})=\# \text { or } \\
& \operatorname{sim}_{\mathrm{c}, \mathrm{w}}\left(\llbracket \mathrm{E} \rrbracket^{\mathrm{c}, \mathrm{s}}, \mathrm{E}^{1}, \llbracket \mathrm{IX}-\mathrm{a} \rrbracket^{\mathrm{c}, \mathrm{s}}\right)=\# \\
1, & \text { iff } \llbracket \mathrm{E} \rrbracket^{\mathrm{c}, \mathrm{s}, \mathrm{w}}\left(\llbracket \mathrm{IX}-\mathrm{a} \rrbracket^{\mathrm{c}, \mathrm{s}, \mathrm{w}}\right)(\mathrm{w})=1 \text { and } \\
& \operatorname{sim}_{\mathrm{c}, \mathrm{w}}\left(\llbracket \mathrm{E} \rrbracket^{\mathrm{c}, \mathrm{s}}, \mathrm{E}^{1}, \llbracket \mathrm{IX}-\mathrm{a} \rrbracket^{\mathrm{c}, \mathrm{s}}\right)=1\end{cases}
\end{aligned}
$$

By parity with what we did for the embedded clause in (56a), we can compute the meaning of the role-shifted clause as follows:

$$
\begin{aligned}
& \llbracket \mathrm{E} \rrbracket^{\mathrm{c}, \mathrm{s}, \mathrm{w}}=\llbracket\left[\mathrm{RS}_{\mathrm{a}} \varnothing_{1} 1 \text {-WALK-WITH-ENERGY }\right] \rrbracket^{\mathrm{c}, \mathrm{s}, \mathrm{w}}=\lambda \mathrm{x}_{\mathrm{e}}{ }_{\mathrm{e}} \lambda \mathrm{w}^{\prime}{ }_{\mathrm{s}} \text {. walk- } \\
& \text { with-energy }{ }^{\prime}{ }^{\prime}{ }^{\prime}\left(\mathrm{x}^{\prime}\right)
\end{aligned}
$$

It remains to specify the content of $\operatorname{sim}_{\mathrm{c}, \mathrm{w}}\left(\llbracket \mathrm{E} \rrbracket^{\mathrm{c}, \mathrm{s}}, \mathrm{E}^{1}, \llbracket \mathrm{IX}-\mathrm{a} \rrbracket^{\mathrm{c}, \mathrm{s}}\right)$ in this case. Since the iconic enrichment of $E$ involves a happy face, we propose the specification in (66): 
(66) $\operatorname{sim}_{c, w}\left(\llbracket E \rrbracket^{c, s}, E^{1}, \llbracket I X-a \rrbracket^{c, s}\right)=1$ iff if $\llbracket E \rrbracket^{c, s}(w)\left(\llbracket I X-a \rrbracket^{c, s}\right)(w)=1$, i.e. if walk-with-energy' ${ }^{\prime}(\mathrm{s}(\mathrm{a}))=1,{ }^{45}$ then $\mathrm{s}(\mathrm{a})$ walks with a happy face in $\mathrm{w} ; 0$ otherwise.

This makes it possible to offer truth conditions for (63b) (we simplify the derivation by noticing that in view of (65) and (66) the meaning obtained will be bivalent).

$\llbracket(63 \mathrm{~b}) \rrbracket^{\mathrm{c}, \mathrm{s}, \mathrm{w}}$

$=1$ iff $\left[\lambda x^{\prime}{ }_{e} \lambda w^{\prime}{ }_{s}\right.$. walk-with-energy $\left.{ }^{\prime}{ }^{\prime}\left(x^{\prime}\right)\right](s(a))(w)=\operatorname{sim}_{c, w}\left(\llbracket E \rrbracket^{c, s}, E^{1}\right.$, $\left.\llbracket \mathrm{IX}-\mathrm{a} \rrbracket^{\mathrm{c}, \mathrm{s}}\right)=1 ; 0$ otherwise

$=1$ iff walk-with-energy' ${ }_{\mathrm{w}}(\mathrm{s}(\mathrm{a}))=1$ and $\mathrm{s}(\mathrm{a})$ walks with a happy face in $\mathrm{w} ; 0$ otherwise

Finally, we can use the definition of truth in (38) to obtain final truth conditions:

(68) If (63b) is uttered in a context c, if the assertion of that sentence is intended to hold in a domain of situations $\mathrm{D}_{\mathrm{c}}$ in the world of $\mathrm{c}$, and if the assignment function s properly represents the referential intentions of the speaker of $\mathrm{c}$, (63b) is true iff for some situation $w$ in the intended domain $D_{c}, s(a)$ walks with energy in w, and s(a) walks with a happy face in w; it is false otherwise.

This seems appropriate.

It remains to check that the role-shifted sentence is interpreted maximally iconically, as this is mandated by Condition (62). Since the entire clause has an iconic index, the only way for it to be interpreted 'more' iconically would be for the iconically interpreted constituent to get a quotational index, say 0 . But intuitively this would yield a failure: in (63), the role-shifted clause denotes a function with a propositional type $(\langle\mathrm{e},\langle\mathrm{s}, \mathrm{t}\rangle\rangle)$, but it is used as a functor applied to an individual and then to a situation argument, not as the argument of an attitude verb denotation. Therefore the evaluation of that propositional element with a linguistic expression should make no sense. Technically, this is enforced by the boldfaced condition in (55), whose effect is to require that a quotational index should appear on a propositional expression used as an argument, not as a functor. The upshot is that we cannot replace the non-quotational index we have in (64) with a quotational one. Thus the interpretation we derived for the role-shifted clause is already 'maximally iconic'.

$45 \overline{\text { By the notational convention in (34a), }} \llbracket \mathrm{E} \rrbracket^{\mathrm{c}, \mathrm{s}}=\lambda \mathrm{w}_{\mathrm{s}} \cdot \llbracket \mathrm{E} \rrbracket^{\mathrm{c}, \mathrm{s}, \mathrm{w}}$, hence $\llbracket \mathrm{E} \rrbracket^{\mathrm{c}, \mathrm{s}}=\lambda \mathrm{w}_{\mathrm{s}} \cdot \lambda \mathrm{x}^{\prime}{ }_{\mathrm{e}} \lambda \mathrm{w}^{\prime}{ }_{\mathrm{s}}$. walk-with-energy' ${ }^{\prime}$ ' $\left(x^{\prime}\right)$ (using the value computed in (65)). Abstraction over $w$ is vacuous, and thus $\llbracket E \rrbracket^{c, s}(w)\left(\llbracket I X-a \rrbracket^{c, s}\right)(w)=\left[\lambda x^{\prime}{ }_{e} \lambda w^{\prime}{ }_{s}\right.$. walk-with-energy' $\left.{ }^{\prime},\left(x^{\prime}\right)\right](s(a))(w)=$ walk-withenergy' ${ }_{w}(s(a))$. 
Super monsters II

\subsection{Attitude Role Shift}

Turning to Attitude Role Shift, we will now explain how (69a), analyzed as (69b) (with the quotational index 0 ) gives rise to a quotational reading for the entire clause, including the happy face on it. (The happy face :-) is understood to appear over the entire role-shifted clause; being non- linguistic, :-) doesn't affect the semantic interpretation, except for its iconic contribution).

$$
\frac{:-)}{\mathrm{RS}_{\mathrm{a}}}
$$
a. IX-a SAY
IX-1 WILL LEAVE
b. IX-a SAY

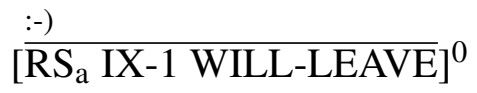

We already did most of the work in (56) in Section 4.3, where we saw how a role-shifted clause under Attitude Role Shift ends up being both used (in indirect discourse) and quoted (in direct discourse). The derivation is identical for (69), except that the role-shifted clause involves a happy face, which is taken to be part of the quotation.

(70) Writing $R^{0}$ for $\left[\overline{\mathrm{RS}_{\mathrm{a}} \mathrm{IX}-1 \mathrm{WILL}-\mathrm{LEAVE}}\right]^{0}$, $\llbracket(69 b) \rrbracket^{c, s, w}=1$ iff for every c' $\in \operatorname{SAY}_{\mathrm{w}}(\mathrm{s}(\mathrm{a}))$, will-leave' ${ }_{\mathrm{c}^{\prime}{ }_{\mathrm{w}}}\left(\mathrm{c}^{\prime}{ }_{\mathrm{a}}\right)=1$ and in $\mathrm{w} \llbracket \mathrm{R} \rrbracket^{\mathrm{c}, \mathrm{s}}$ is expressed by $R^{0} ; 0$ otherwise.

We note that $\llbracket \mathrm{R} \rrbracket^{\mathrm{c}, \mathrm{s}}=\lambda \mathrm{w}{ }_{\mathrm{s}} \lambda \mathrm{x}{ }{ }_{\mathrm{e}} \lambda \mathrm{w}{ }_{\mathrm{s}}$ will-leave' ${ }_{\mathrm{w}},\left(\mathrm{x}{ }^{\prime}\right) .{ }^{46}$

Applying the definition of truth in (38), we obtain:

(71) If (69b) is uttered in a context $c$, if the assertion of that sentence is intended to hold in a domain of situations $\mathrm{D}_{\mathrm{c}}$ in the world of $\mathrm{c}$, and if the assignment function s properly represents the referential intentions of the speaker of $\mathrm{c}$, (69b) is true iff for some situation $w$ in the intended domain $D_{c}$, for every $\mathrm{c}^{\prime} \in \mathrm{SAY}_{\mathrm{w}}(\mathrm{s}(\mathrm{a}))$, will-leave' ${ }_{\mathrm{c}}{ }_{\mathrm{w}}{ }_{\mathrm{w}}\left(\mathrm{c}^{\prime}{ }_{\mathrm{a}}\right)=1$ and in $\mathrm{w} \lambda \mathrm{w}_{\mathrm{s}}{ }_{\mathrm{s}} \lambda \mathrm{x}_{\mathrm{e}} \lambda_{\mathrm{w}}{ }_{\mathrm{s}}$ willleave' ${ }_{\mathrm{w}}$ ( $\left(\mathrm{w}\right.$ ') is expressed by $R^{0} ; 0$ otherwise; or in other words, (69b) is true iff for some for some situation $w$ in the intended domain $D_{c}$, for every context c' compatible with what s(a) claims in $\mathrm{w}$, the agent of c' will leave in the world of c', and the embedded proposition is expressed by the very words I will leave (in ASL).

46 Specifically $\llbracket \mathrm{R} \rrbracket^{\mathrm{c}, \mathrm{s}}=\lambda \mathrm{w}_{\mathrm{s}} \mathrm{s} \cdot \llbracket \mathrm{R} \rrbracket^{\mathrm{c}, \mathrm{s}, \mathrm{w}^{\prime}}=\lambda \mathrm{w}_{\mathrm{s}} \llbracket \mathrm{RS}_{\mathrm{a}}$ IX-1 WILL-LEAVE $\rrbracket^{\mathrm{c}, \mathrm{s}, \mathrm{w}}=\lambda \mathrm{w}^{\prime}{ }_{\mathrm{s}} \lambda \mathrm{x}_{\mathrm{e}}{ }_{\mathrm{e}} \lambda \mathrm{w}_{\mathrm{s}}$ \IX-1 WILL-LEAVE $\rrbracket^{\left\langle x^{\prime}, w^{\prime}\right\rangle, s, w^{\prime}}$. It is thus a constant function (over its first argument) of type $\langle\mathrm{s},\langle\mathrm{e}$, $\langle\mathrm{s}, \mathrm{t}\rangle\rangle\rangle$. See fn. 41 for ways to make more precise what it takes for such a function to be 'expressed' by $R^{0}$ in the situation w. 
This implies that in the situation of evaluation $\mathrm{w}$, the meaning of the embedded clause is expressed by the very words that appear in the embedded clause; this comes close to the desired result, namely that the very words that appear in the embedded clause were uttered by the agent of the reported speech act.

\subsection{Distinctions among attitude verbs}

Given the present analysis of Attitude Role Shift, role-shifted clauses should have a quotational component. This leads one to expect that Attitude Role Shift should be more natural with verbs of speech than with verbs of thought. Preliminary ASL data suggest that this is so. Specifically, the table under (72) lists our ASL consultant's acceptability ratings for a sentence of the form (72i), with a verb of speech and no Role Shift, and for a minimally different sentence of the form (72ii), with the same verb of speech and a role-shifted embedded clause. The table under (73) does the same thing, but for verbs of thought. Overall, verbs of speech allowed for both constructions with high acceptability, whereas for verbs of thought Role Shift was often slightly dispreferred. We take this to be compatible with the present analysis, since verbs of speech presumably introduce direct discourse a bit more easily than verbs of thought. A more detailed typology and analysis are left for future research. ${ }^{47}$

$\mathrm{John}_{\mathrm{a}}\langle$ verb of speech $\rangle$

i. IX-a WILL LIVE WITH MARY

$\mathrm{RS}_{\mathrm{a}}$

ii. IX-a WILL LIVE WITH MARY

(ASL, 19, 37)

\begin{tabular}{|l|c|c|}
\hline$\langle$ verb of speech $\rangle=$ & (i) No Role Shift & (ii) Role Shift \\
\hline 1. SAY & 7 & 6.3 \\
\hline 2. TELL-1 & 7 & 6.7 \\
\hline 3. ANNOUNCE & 7 & 6.7 \\
\hline 4. TELL (story) & 7 & 7 \\
\hline 5. EXPLAIN & 6.7 & 6.7 \\
\hline 6. INFORM-1 & 7 & 6.3 \\
\hline
\end{tabular}

47 In a session in which our consultant obtained contrasts in acceptability among verbs of saying with Role Shift, he suggested that verbs that are 'native' to the ASL vocabulary might accept Role Shift more easily than those that are borrowed from English. We leave this hypothesis for future research. 
Super monsters II

(73) $\mathrm{John}_{\mathrm{a}}\langle$ verb of thought $\rangle$

i. IX-a WILL LIVE WITH MARY

$\mathrm{RS}_{\mathrm{a}}$

ii. IX-a WILL LIVE WITH MARY

\begin{tabular}{|l|c|c|}
\hline$\langle$ verb of thought $\rangle=$ & (i) No Role Shift & (ii) Role Shift \\
\hline 1. THINK & 7 & 4.7 \\
\hline 2. THINK 2 (deeply) & 6.7 & 4.7 \\
\hline 3. KNOW & 7 & 5.3 \\
\hline 4. WONDER & 6.3 & 5.3 \\
\hline 5. IMAGINE & 7 & 6.7 \\
\hline 6. FEEL & 7 & 6 \\
\hline
\end{tabular}

Three technical remarks should be made to conclude this section.

- We have not been concerned in this discussion with the typology of indexicals developed in Part I in relation to the distinction between Attitude and Action Role Shift. Briefly, the framework we had developed at that point was typetheoretic (albeit with more complex types than in the present discussion, in order to distinguish between 'primitive' and 'derived' contexts), and it too could be enriched with the sort of iconic component we developed in this part.

- We explained in Part I that our choices for the Role Shift operator are motivated by its interaction with quotational effects. Problems that arise with alternative choices are discussed in Appendix $\mathrm{C}$ of the present part.

- It would be very natural to develop the analysis within an event semantics rather than a situation semantics (albeit at the cost of making the connection with standard intensional analyses of context shift less transparent). In such a framework (used for the analysis of Role Shift in Davidson 2015), quantification over situations is replaced with quantification over events/states, and these come with thematic roles such as agent, patient, theme, etc. This would make it possible to offer a more articulated analysis of the truth conditions of (70), one in which the final requirement is that there is an event which is a saying, whose agent is individual $a$, whose theme is the centered proposition corresponding to I will leave, and whose theme is expressed by the very words IX-1 WILL-LEAVE. We leave such refinements for future research. 
Philippe Schlenker

\section{Necessary Refinements: ASL vs. LSF}

\subsection{ASL vs. LSF I: Strict or non-strict quotation?}

We saw in Part I that our ASL consultant and our LSF consultant have different judgments with respect to $w h$-extraction: only in ASL was $w h$-extraction allowed under Attitude Role Shift. Given the present framework, the simplest way to capture this contrast is to posit that quotational iconic functions are more permissive in ASL than in LSF, in that in ASL but not in LSF they may ignore $w h$-traces, as stated in (74).

\section{(74) Quotational iconic functions}

a. Strict version - LSF $\ldots \llbracket \mathrm{F} \rrbracket^{\mathrm{c}, \mathrm{s}}$ is expressed in w by the string $F$

b. Liberal version - ASL

$\ldots \llbracket \mathrm{F} \rrbracket^{\mathrm{c}, \mathrm{s}}$ is expressed in w by a string $F^{*}$ obtained from $F$ by (possibly) replacing $w h$-traces with expressions of the same syntactic and semantic type. $^{48}$

Consider for instance the case of $w h$-extraction in (75a), discussed for ASL sentences in Part I; we take it to have the Logical Form in (75b), and we only provide a derivation of its truth conditions under a particular assignment function $\mathrm{s}$.
a. WHO IX-a SAY $\frac{\text { RS }}{\text { IX-1 WILL LIVE WITH HERE }}{ }^{49}$

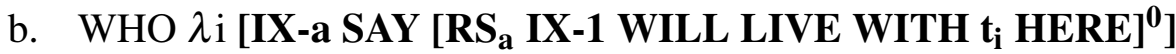
a. IX-a SAY $\left[\mathrm{RS}_{\mathrm{a}}\right.$ IX-1 WILL LIVE WITH $\mathrm{t}_{\mathrm{i}}$ HERE $^{0}$
b. We write $E^{0}=\left[\mathrm{RS}_{\mathrm{a}} \text { IX-1 WILL LIVE WITH } \mathrm{t}_{\mathrm{i}} \text { HERE }\right]^{0}$, and we assume that for every c', s', w', author of c' and c' 1 is the location of c'.
Noting that no presupposition failure is obtained for type reasons, we can compute:
$=1$ iff for every c' $\in \mathrm{SAY}_{\mathrm{w}}(\mathrm{s}(\mathrm{a}))$, will-live-with' ${ }_{\mathrm{c}^{\prime}{ }_{\mathrm{w}}}(\mathrm{s}(\mathrm{i}))\left(\mathrm{c}^{\prime}{ }_{\mathrm{a}}\right)\left(\mathrm{c}_{1}\right)=1$ and

48 We could consider adding a requirement that a trace $t_{i}$ should be replaced by an expression that denotes the same thing as $t_{i}$, but this would require a more sophisticated analysis where possible replacements are considered relative to an assignment function.

49 The full sentence is reproduced in (i):

(i) Context: The speaker is in NYC; the listener was recently in LA with John. BEFORE IX-a JOHN IN LA [ = while in LA],

6.7 WHO IX-a SAY IX-1 WILL LIVE WITH HERE WHO

'While John was in LA, who did he say he would live with there?' (ASL, 14, 91) 
Super monsters II

in $\mathrm{w} \llbracket \mathrm{E} \rrbracket^{\mathrm{c}, \mathrm{s}}$ is expressed by an expression $\mathrm{E}^{*}$ obtained from $\mathrm{E}$ by (possibly) replacing $t_{i}$ with an expression of the same syntactic and semantic type; 0 otherwise

$=1$ iff for every c' $\in \operatorname{SAY}_{\mathrm{w}}(\mathrm{s}(\mathrm{a}))$, will-live-with' ${ }_{\mathrm{c}_{\mathrm{w}}}(\mathrm{s}(\mathrm{i}))\left(\mathrm{c}^{\prime}{ }_{\mathrm{a}}\right)\left(\mathrm{c}_{1}\right)=1$ and in $\mathrm{w}$ for some nominal expression $\mathrm{n}$ of type $\mathrm{e}, \llbracket \mathrm{E} \rrbracket^{\mathrm{c}, \mathrm{s}}$ is expressed by IX-1 WILL LIVE WITH $n$ HERE; 0 otherwise

Thus the wh-trace does not have to be quoted, though the rest of the clause does - which appears to be adequate for this particular case. ${ }^{50}$

In effect, the liberal condition in (74b) allows for a kind of 'mixed quotation' in which $w h$-traces are selectively ignored. It would be tempting to make the liberal version a bit more general by stating that all empty categories can be ignored in this way. But this requires some caution: as we noted in Section 2.2, in ASL and LSF alike an elided VP under Attitude Role Shift is interpreted quotationally, in the sense that it gives rise to the inference that the original speech act involved an ellipsis as well. Thus we do not want the liberal version of quotational iconic functions to treat elided elements in the same way as $w h$-traces. Pending further investigation, then, we stick to this somewhat restrictive version of the liberal principle.

\subsection{ASL vs. LSF II: Exhaustive Iconicity}

In Attitude Role Shift, the rule of Maximal Iconicity in (62) will force the appearance of a quotational index on the role-shifted clause. But should Action Role Shift always include an iconic component? The following example from Part I might suggest that in ASL this isn't always the case; however the example is hard to interpret because the repetition involved in the realization of the verb GIVE might be taken to have an iconic component.

IX-a JOHN OFTEN MEET-MEET [POOR PEOPLE] $]_{b}$, IX-1 KNOW LOTS PEOPLE IX-arc-b IX-a FINISH

'John often meets poor people. I know lots of people that he $\mathrm{RS}_{\mathrm{a}}$ 7 1-GIVE-b-rep MONEY.

has given money to.' (ASL, 18, 98; from Part I)

Our consultant often remarked that Role Shift had to be justified by something. This condition is not derived by our current system. If the role-shifted expressions do

50 We must note, however, that in the general case this account will have to be made more sophisticated. This is because in sentences in which the subject is quantified - e.g. Who did every student say he would share an apartment with? — we must allow for the possibility that different students used different descriptions in sentences of the form I will share an apartment with $X$. As it stands, our account fails to allow for this provision. We leave this problem for future research. 
not lend themselves to an iconic interpretation, the function $\operatorname{sim}_{c, w}$ that interprets iconic indices in our interpretive rules in (44) will arguably yield a failure; in which case the rule of Maximal Iconicity in (62) will not mandate that any iconic indices appear. If we wish to ensure that Role Shift is always justified by something, we need to posit a condition such as (78), which requires that at least one element under Role Shift should be interpreted iconically. (In the case of (77), this condition might in fact be satisfied if repetition of the verb is iconically mapped to the repetition of giving events.)

\section{(78) Economy condition on Role Shift (ASL and LSF)}

Role Shift should be justified by something - usually, at least one role-shifted expression should have an iconic component.

Be that as it may, even this condition won't be enough to account for the LSF data discussed in Part I, which suggested that under ill-understood conditions, expressions that don't have a proper iconic component trigger an attitude reinterpretation. In our data, this was for instance the case for (79a): neither IPHONE nor the general verb $\mathrm{SHOW}-(a)$ has an iconic component, and the entire role-shifted clause was understood to be in the scope of a covert attitude operator. In (79b) we obtained a mixed reading in which $I P H O N E$ was cited but $S H O W-C L$ corresponded to an action.

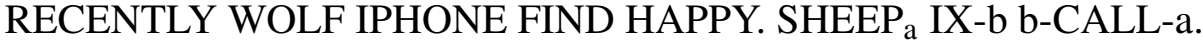
'Recently the wolf was happy to find an iPhone. He called the sheep.

a. $\quad$ 6.7 IX-b IPHONE 1-SHOW-a.

$\Rightarrow$ the wolf said/thought he was showing/would show the iPhone to him $\mathrm{He}$ [= the wolf] said/thought he would show/was showing the iPhone to him.'

b. 7 IX-b $\frac{\mathrm{RS}_{\mathrm{b}}}{\mathrm{IPHONE} 1-\mathrm{SHOW}-\mathrm{CL}-\mathrm{a}}$.

$\Rightarrow$ the wolf said 'iPhone' and showed the iPhone (see full ratings in Appendix IV)

He [= the wolf] said '(an) iPhone' and showed it.'

(LSF, 39, 37; see also LSF, 39, 27)

In (80a) we have copied our tentative generalization, made in (29) above; it could be implemented in the present framework as in (80b). ${ }^{51}$

51 Note that in LSF (80b) makes (78) redundant. But despite initial appearances (80b) as it stands cannot fully replace 'Maximal Iconicity' as stated in (61). The reason is that the latter includes a requirement that quotational indices be used whenever possible, whereas (80) is silent on this issue. 
Super monsters II

(80) Exhaustive Iconicity (LSF consultant; tentative)

a. Informal version: In LSF, every word under Role Shift must have an iconically interpreted component.

b. Formal version: In LSF, every word under Role Shift should be included in a constituent with an iconic index.

As things stand, we can only make the following suggestions about (79):

- In (79a), neither IPHONE nor SHOW has a plausible iconic, non-quotational component. If only 'Maximal Iconicity' as in (61) were in force, the sentence would be acceptable, since given this Logical Form the sentence is interpreted as iconically as it could be: no non-quotational iconic interpretation is available given the signs that appear under Role Shift, and adding quotational indices would presumably yield a semantic failure. But given Exhaustive Iconicity as stated in (80), the only way out is to apply a rescue strategy that consists in introducing a concealed attitude operator, which we write as $S A Y$ (this is similar to the strategy discussed in Part I to 'save' indexicals that appear under Role Shift in the absence of an overt attitude operator). This leads to the Logical Form in (81), which is now compatible with the insertion of a quotational index 0 on the entire role-shifted constituent - which leads us back to the situation we discussed in (69b).

\section{IX-b SAY $\left[\mathrm{RS}_{\mathrm{b}} \text { IPHONE SHOW }\right]^{0}$}

- We cannot account for the mixed interpretation which is apparently found in (79b). If we assign to IPHONE a quotational index 0 and to $S H O W-C L$ an iconic, non-quotational index 1, as shown in (82), we will have satisfied Exhaustive Iconicity as stated in (80). But as things stand we cannot add a quotational iconic index on the word IPHONE alone, which is not of a propositional type (as required by (55)). Both the facts and the analysis are left for future research.

\section{IX-b RS IPHONE $^{0}$ SHOW-CL $^{1}$}

\section{An Alternative? Role Shift as Demonstration}

Davidson 2015 offers an interesting alternative to (an earlier version of) the present analysis. Following Lillo-Martin 1995, 2012, she takes Role Shift to signal the presence of a demonstration, somewhat like the expression 'be like' in English, which has both quotational and co-speech uses, as illustrated in (83). 
(83) a. John was like "I'm happy".

b. Bob was eating like [gobbling gesture]. (Davidson 2015)

Davidson describes her main intuition as follows:

the English expression "be like" is the closest equivalent to role shift in sign languages, but instead of a silent "be like" that embeds the action report as a proposition, I tie the two together through the semantics of predicate modification, so that the entire action report is a monoclausal structure. The idea here is that the RS morpheme, in contrast to English "like", is produced simultaneously with other lexical material, consistent with a tendency toward simultaneous verbal morphology in sign languages versus sequential morphology in spoken languages (Klima \& Bellugi 1979).

Davidson takes the signer's body to play an essential role in the demonstration, namely of representing the agent whose speech or actions are represented. Following Supalla 1982, she likens Role Shift to 'classifier predicates', which were analyzed by Zucchi et al. 2012 as involving a (self-referential) demonstration. For instance, in (84) the verbal classifier $C L-B$ serves to specify by way of a demonstration the position of the table.

(84) TABLE CL-B(Outline of the shape of the table)

'There is a table like this.' (Davidson 2015)

Importantly, for Davidson no context shift is involved: the signer's body represents another individual in the same way as the classifier $C L-B$ in (84) represents an object, but no special operation of context shift is needed to account for Role Shift.

Davidson analyzes ASL and LSF Attitude Role Shift as being plainly quotational. She develops a demonstrative analysis of quotation within an event semantics in which certain events may involve demonstrations, as is illustrated in (85).

$\llbracket J o h n$ said “I'm happy" $=\exists$ e. [agent(e, John) \& demonstration $\left.\left(\mathrm{d}_{1}, \mathrm{e}\right)\right]$, where "I'm happy" denotes the demonstration $\mathrm{d}_{1}$ (Davidson 2015 (32))

Davidson then extends her analysis to Action Role Shift by taking role-shifted verbs to have a demonstrative component as well, as suggested by the contrast within LSF between (28a) and (28b) above. Agreeing with part of our analysis, Davidson takes the iconic verb $S H O W-C L$ to have a demonstrative/iconic component that the non-iconic verb SHOW lacks, and she takes this to explain why only the former is acceptable under Action Role Shift. Technically, Davidson posits the same lexical entry for Role Shift and for the English word like, as shown in (86). 
Super monsters II

(86) a. $\llbracket$ like $\rrbracket=\lambda \mathrm{d} \lambda \mathrm{e}[\operatorname{demonstration}(\mathrm{d}, \mathrm{e})]$

b. $\llbracket \mathrm{RS} \rrbracket=\lambda \mathrm{d} \lambda \mathrm{e}[\operatorname{demonstration}(\mathrm{d}, \mathrm{e})]$

Davidson's system derives the following denotation for (28b), where $d_{l}$ is the demonstration effected simultaneously with the production of the iconic sign $S H O W$ $C L$ (which Davidson transcribes as $\mathrm{SHOW}$; we use our own transcription for clarity).

«WOLF IPHONE SHOW-CL rs [gesturally appropriate hand shape and movement]』

$=\exists$ e $\left[\operatorname{agent}(\mathrm{e}\right.$, wolf $) \&$ theme $(\mathrm{e}$, iphone $) \&$ showing (e) \& demonstration $\left.\left(\mathrm{d}_{1}, \mathrm{e}\right)\right]$, where the value of $d_{l}$ is given by the iconic properties of SHOW-CL (Davidson $2015(68))$

Importantly, in this analysis some verbs can appear in Action Role Shift because they lexically have a demonstrative/iconic component, hence the difference between LSF SHOW and LSF SHOW-CL. But for Davidson it is not clear what it would mean for an entire VP or a larger structure to be interpreted demonstratively in such cases, and thus she argues that arguments of the verb must be 'moved out' before Action Role Shift can be applied. ${ }^{52}$ In fact, she argues that "most examples of reported action in previous sign language literature involve just the predicate under role shift, not any further arguments and certainly not an entire clause (Engberg-Pedersen 1995; Lillo-Martin 1995, 2012”, and she thus takes it as a positive feature of her proposal that it allows for Action Role Shift over verbs but not over larger constituents.

There are some similarities and some differences between the present account and Davidson's interesting alternative. Let us start with the similarities. First, Davidson writes of signs that have a (self-referential) demonstrative and gestural component rather than an iconic component, but this is almost entirely a terminological difference. What counts as a demonstration and how it works is left entirely open in Davidson's proposal, and it could just be taken to be the iconic component discussed in this piece. ${ }^{53}$ Second, the two accounts agree that in Attitude and Role Shift alike, the role-shifted expressions have an iconic component. In particular, both assume that in Action Role Shift the words are both used and mentioned. Third, we have followed Davidson in taking the iconic component to be interpreted by way of conjunctive modification ${ }^{54}$. And it is primarily to retain a clear connection with standard intensional accounts of context shift that we developed our analysis within

52 It is not clear to me why a variant of Davidson's analysis couldn't allow for Action Role Shift over longer expressions, as long as the entire role-shifted expression has a demonstrative/iconic component. This would bring Davidson's analysis one step closer to the present one.

53 One potential difference lies in the connections that Davidson's account leads one to expect with (i) explicitly demonstrative constructions, and possibly (ii) co-speech gestures in spoken language.

54 An earlier version of this piece gave a different treatment of iconic enrichments. 
a situation - theoretic rather than in an event-theoretic semantics - the latter could be used to make some aspects of the present analysis more precise.

Still, there are important differences between the two analyses, both for Attitude and for Action Role Shift. First, Davidson takes Attitude Role Shift to be a pure case of quotation. This doesn't explain why wh-extraction is possible out of Attitude Role Shift in our ASL data, but since there are other arguments for taking these constructions to be quotational (e.g. the behavior of $A N Y$ ), she doesn't take this to be a problem; and she correctly notes that this is a virtue for the LSF data we discussed above. On the other hand, Davidson doesn't say how her account would extend to languages such as Catalan and German Sign Language, which according to the literature allow for mixing of perspectives (see Quer 2005, 2013, Herrmann \& Steinbach 2012, and Part I of the present study). By contrast, the present analysis posits that in Attitude Role Shift expressions are both used and quoted. This allows for full semantic integration of the role-shifted clause, as well as for grammatical dependencies - as long as the quotational component is satisfied. The latter would need to be parametrized to account for mixing of perspectives in Catalan and German Sign Language, but as we saw, such a parametrization might already be needed to explain some differences between our ASL and our LSF data. And as noted in Part I, the Catalan and German Sign Language pattern might be unsurprising in view of the typology of context-shifting constructions in spoken language (discussed for instance in Schlenker 2011).

Second, as it stands Davidson's analysis predicts that Action Role Shift should only apply to verbs, not to larger structures - since for her the demonstration we find in Action Role Shift is part of the lexical specification of the verb. Given Davidson's claim that the arguments of a verb must be 'moved out' before it can undergo Action Role Shift, this seems to be a good thing. But some of the data we elicited from our ASL consultant appear to allow larger structures to appear under Action Role Shift if they contain no overt indexical other than the first person agreement marker, as shown by (88a) ((88b)-(88d) are deviant and/or give rise to an attitude reinterpretation; this paradigm is repeated from Part I). And the LSF sentence in (31) above also involved Action Role Shift over both a verb and a noun phrase. Within our analysis, such structures can be interpreted under Action Role Shift, with the possible proviso that some or all elements should have an iconic component. These structures should thus be investigated in greater detail in the future. 
Super monsters II

(88) YESTERDAY IX-1 1,a-MEET JOHN

'Yesterday I met John. He

$\mathrm{RS}_{\mathrm{a}}$

a. $6 \longdiv { 1 - E M A I L - r e p ~ F R I E N D S . ~ }$

Rightarrow John did/will email people

was emailing (his) friends

$\mathrm{RS}_{\mathrm{a}}$

b. $\quad 3.7$ 1-EMAIL-rep POSS-1 FRIEND.

$\Rightarrow$ John said he was emailing people (but see the detailed inferential judgments in Appendix IV) said he was emailing his friends.'

$\mathrm{RS}_{\mathrm{a}}$

c. $\quad 5.7 \overline{\mathrm{IX}-1}$ 1-EMAIL-rep FRIENDS.

Rightarrow John said he was emailing people

said he was emailing friends.'

$\mathrm{RS}_{\mathrm{a}}$

d. 6 IX-1 1-EMAIL-rep POSS-1 FRIEND.

Rightarrow John said he was emailing people

said he was emailing his friends.'

(ASL, 19, 214; repeated from Part I)

Finally, it seems to us that there is a serious tension within Davidson's account. On the one hand, she argues that in Attitude Role Shift the words are mentioned/demonstrated, not used, since she says explicitly that Role Shift "actually is quotation" (p. 499). On the other hand, she posits that in Action Role Shift the verbs are both used and demonstrated. A symptom of this differential treatment is that different kinds of Logical Forms seem to be posited for quotational constructions as in (85), and for Action Role Shift as in (87) (she does not provide explicit Logical Forms for Attitude Role Shift, but it is clear that quotation is what she has in mind). Specifically, in (85) the quoted clause only enters the truth conditions by way of a demonstration: the words are entirely mentioned/demonstrated, not used. In (87), by contrast, the verb $S H O W-C L$ is both used as a normal verb, and mentioned/demonstrated. But this raises a question: why does the mechanism that allows verbs in Action Role Shift to be both used and mentioned not also allow words to be both used and mentioned in Attitude Role Shift as well? This would take Davidson's theory one step closer to the present analysis, especially if one observes, as we did above, that the distinction between what she calls 'gestural' and what we call 'iconic' is primarily terminological. 
Philippe Schlenker

\section{Conclusion}

In Part I, we argued that Role Shift is a 'super monster' because it does not just shift the context of evaluation of indexicals in attitude reports ('Attitude Role Shift'), but also in some extensional environments ('Action Role Shift' — with severe constraints on which indexicals can be 'shifted' in this way). In this part, we saw that Role Shift is a 'super monster' in a second sense: it doesn't just shift contexts, but comes with iconic conditions as well, requiring that expressions under Role Shift should be interpreted maximally iconically.

Several conclusions can be drawn from the present study.

(i) In Part I, we suggested that Role Shift makes overt the operation of 'context shift' that was postulated on the basis of somewhat indirect evidence in spoken language. We further argued that the cross-linguistic typology of Attitude Role Shift - with some languages allowing for mixing of perspectives, and others disallowing it - mirrors a typology found in spoken language. In the case of ASL and LSF, it proved difficult to exclude a quotational analysis of Attitude Role Shift (by contrast, mixing of perspectives in Catalan and German Sign Language does argue against a simple quotational analysis in these languages). Still, for Action Role Shift, a context-shifting analysis turned out to be mandatory given our ASL and LSF data: because the relevant constructions described actions rather than attitudes, it just wasn't feasible to take the role-shifted clause to be mentioned rather than used. (As we emphasized in Part I, the theory of indexicals must be parametrized to capture the fact that all indexicals are shifted under Attitude Role Shift, whereas most indexicals are unacceptable or lead to an attitude reinterpretation in Action Role Shift.)

(ii) Still, we now understand why quotational analyses of Attitude Role Shift are hard to disprove - quite simply, they are partly correct. But the quotational effects found in ASL and LSF Attitude Role Shift are part of a more general phenomenon: in all cases, Role Shift is interpreted maximally iconically; quotation is just a special case of iconicity, one in which the iconically interpreted words are type-identical to words uttered in the denoted situations. As noted in Part I, we obtained contrasting judgments between our ASL and our LSF consultants with respect to wh-extraction out of Attitude Role Shift (acceptable in our ASL data, unacceptable in our LSF data). We accounted for this contrast by parameterizing what counts as an appropriate iconic/quotational contribution. Specifically, we did so in the pragmatics, by postulating that the similarity relations involved in quotations are more liberal in ASL than they are in LSF. We also suggested - tentatively - that our ASL consultant just obeys a rule of 'Maximal Iconicity' under Role Shift, whereas for our LSF 
Super monsters II

consultant a rule of 'Exhaustive Iconicity' is also in force, whereby each word under Role Shift must have an iconic component.

(iii) Due to the complexity of the subject matter, many important empirical and theoretical questions are left for future research.

- On a theoretical level, our formal semantics with iconicity is in a rather preliminary stage. Following Davidson 2015, we took iconic enrichments to behave like modifiers, which contribute at-issue constraints on the situation parameter (rather than on an event variable, as in Davidson's treatment). But we only gave examples of how the enrichment can be effected. More importantly, the structure of our theory might leave something to be desired. In effect, we had to postulate two independent mechanisms to account for sign language Role Shift: on the one hand, we needed an operation of context shift; on the other, we posited a principle of iconicity maximization; but these are logically independent from each other. It might seem more desirable to reduce one principle to the other, but achieving this result is non-trivial. ${ }^{55}$

- On an empirical level, we only have the beginning of an understanding of the discourse conditions that license Role Shift, and we have been silent on further constraints that might limit its scope (for instance, there is a common impression that Role Shift is less acceptable under negation; we come back to this issue in Appendix A). Furthermore, we only have the beginning of an understanding of possible contrasts between ASL and LSF Role Shift. Even more importantly, one should determine whether the iconic effects discussed hold in other sign languages, in particular in Catalan Sign Language (LSC) and in German Sign Language (DGS): since these allowed some indexicals under Attitude Role Shift to be evaluated from the signer's rather than from the agent's perspective, at least these expressions must escape the requirement that they be quoted; it would be particularly important to establish whether further iconic effects that are obligatory or near-obligatory in ASL and LSF are weaker or non-existent in LSC and DGS. ${ }^{56}$

\footnotetext{
55 One might want to reduce apparent context shift to iconicity, along the lines of Maier's quotationbased reanalysis of shifted indexicals (Maier 2014b); but extending this analysis to Action Role Shift is non-trivial. Alternatively, one might want to reduce iconicity maximization to context shift. But the difficulty is that (some) iconic effects appear to enrich the 'normal' at-issue component of words, as in the case of GROW in (32). In our implementation, this ends up putting constraints on the world rather than on the context of evaluation, and it is the latter that would be crucial for a context-shifting analysis to directly account for iconic effects.

56 This point was raised by the audience during a talk at University of Pennsylvania.
} 
- On a methodological level, the facts would need to be replicated and extended with further signers; at this point, our generalizations are just based on in-depth, long-term fieldwork with one ASL signer and one LSF signer. On the other hand, the method we used - based on repeated and quantitative judgments - is an improvement over informal methods of data collection, and it could pave the way for a more systematic (and possibly experimental) approach in the future.

(iv) While our formal analysis of iconic meaning is preliminary, a key component of it is that the meaning of an expression can be enriched by conditions that make reference to its shape. When applied to Attitude Role Shift, this has the consequence that some expressions are both used (with their normal meaning) and quoted. As noted in Section 4.4, this makes our analysis partly similar to several recent theories of quotation, although the precise relation between Role Shift and partial quotation has yet to be investigated.

(v) This study raises new questions about the comparison between signed and spoken languages.

- Do the quotational effects we found in Attitude Role Shift have counterparts in some indirect discourse constructions in spoken language? Pearson 2012 notes potential quotational effects in some Ewe constructions that involve logophoric pronouns - which are a hallmark of indirect rather than direct discourse; still, in her data NPIs are licensed in the same constructions, a point of difference from our ASL data pertaining to Attitude Role Shift. ${ }^{57}$ It might be useful to revisit in some detail different varieties of indirect discourse (especially with logophoric pronouns and with shifted indexicals) to determine whether some of them display the

57 Pearson observed that for her Ewe consultant (i) was 'acceptable, but only if it reports the addressee's words faithfully. For instance, (i) is unacceptable in a scenario where the verb used by the addressee was $y i$, 'go' rather than $d z o$, in which case (ii) should be used instead'.

(i) $\mathrm{O}$ gblon be yè dzo

2SG say COMPL? LOG leave

'You said that you left.' (Pearson 2012 p. 448, fn. 123)

(ii) $\mathrm{O}$ gblon be $\mathrm{o}$ dzo

2SG say COMPL? LOG leave

'You said that you left.' (Pearson 2012 p. 448, fn. 123)

Pearson tentatively concludes that 'in addition to its use in indirect discourse, a (semi-) quotational use of yè may be marginally available'. Importantly, however, in some of Pearson's data NPIs can be licensed from outside a logophorically-marked clause, as in (iii) (Pearson 2012 p. 523). (Thanks to Hazel Pearson for discussion of this point.) 
Super monsters II

kind of 'iconicity maximization' that we saw at work in Attitude Role Shift.

- Does Action Role Shift have counterparts in spoken language? We do not know of clear cases, but it might well be that some will be found. In case none are, one might ask whether the difference in modality might be responsible for this. We suggested by way of the 'economy condition' in (78) that Role Shift has to be justified by something - usually the fact that at least one element has an iconic component. This might explain why it is sometimes difficult to find 'good' examples of Action Role Shift — the reason might be that we had to find signs that could plausibly have an iconic component in the relevant situations. This hypothesis might also explain why under $S A Y$ Role Shift is systematically easier, as in this case the economy condition can be satisfied by treating the role-shifted clause as quoted. If it turns out that context shift in spoken language is subject to the same economy condition as Role Shift in sign language, this condition might explain the absence or near-absence of an equivalent of Action Role Shift in spoken language. Due to the medium, iconic possibilities are very restricted in spoken language, except when it comes to quotational effects. Hence the requirement that role-shifted clauses should have an iconic component should be easy to satisfy in (potential) spoken language counterparts of Attitude Role Shift, but not of Action Role Shift - hence the absence of the latter in the spoken modality. Still, this hypothesis can be maintained only if it can be shown that spoken language has fine-grained counterparts of Attitude Role Shift, i.e. indirect discourse constructions that must be interpreted maximally quotationally. Hence the importance of the question raised in the previous paragraph.

\section{A ANY under Action Role Shift in ASL}

In our ASL data, $A N Y$ is degraded in Action Role Shift even in (apparently) negative environments, as is shown in (89a). The data aren't entirely clear because the control condition we used in (89b) (with Role Shift but without $A N Y$ ) isn't perfect to begin with. Still, $A N Y$ makes the sentence less acceptable. The theory developed in the text explains why ANY cannot be licensed from outside Attitude Role Shift: since the latter comes with a requirement that it should be interpreted quotationally, $A N Y$ should be as unacceptable as in the English sentence: The guard didn't say: 'I showed

(iii) John be $\mathrm{m}$ yè mkpo sukuvi dekpe $\mathrm{o}$

John COMPL NEG LOG NEG.see student any NEG

'John said that he didn't see any students.' 
the prisoners any kindness' (= only acceptable if the guard is claimed to have used an ungrammatical sentence). But this analysis does not extend to Action Role Shift, since 'maximal iconicity' does not translate into quotation in that case.

IX-a JOHN OFTEN MEET-MEET [INJURED PEOPLE] $]_{\mathrm{b}}$, 'John often meets injured people,
a. 3 BUT IX-a NEVER SHOW-b ANY HEART-SOFT.
a'. 5 BUT IX-a NEVER $\frac{\mathrm{RS}_{\mathrm{a}}}{\mathrm{SHOW}-\mathrm{b} \text { HEART-SOFT. }}$ but he never shows them (any) kindness.'
$\mathrm{RS}_{\mathrm{a}}$
b. 2 IX-a OFTEN SHOW-b ANY HEART-SOFT. $\mathrm{RS}_{\mathrm{a}}$
b'. 6 IX-a OFTEN SHOW-b HEART-SOFT. and he often shows them (any) kindness.'
(ASL, 14, 125)

As can be seen in (90), these are approximately the types of contrasts that we obtained with Attitude Role Shift.

IX-a JOHN OFTEN MEET-MEET [INJURED PEOPLE $]_{\mathrm{a}}$, 'John often meets injured people,
a. 2.7 BUT IX-a NEVER SAY IX-1 SHOW-b ANY HEART-SOFT. $\mathrm{RS}_{\mathrm{a}}$
a'. 6 BUT IX-a NEVER SAY IX-1 SHOW-b HEART-SOFT. but he never said to them that he showed kindness.'
b. 2.3 IX-a OFTEN SAY IX-1 SHOW-b ANY HEART-SOFT. $\mathrm{RS}_{\mathrm{a}}$
b’ 6.7 IX-a OFTEN SAY IX-1 SHOW-b HEART-SOFT. and he often said to them 'I show (you) (my) kindness." (ASL, 14, 129)

The deviance of the control sentence with Action Role Shift and a negative expression might give us a hint as to the reason. It might be that in Action Role Shift, a presupposition-like ${ }^{58}$ inference is triggered to the effect that the iconically interpretable features of the role-shifted clause can be mapped to a situation in the

58 Note that we speak of a 'presupposition-like' inference to refer to one that projects from the scope of negative expressions. But for the analysis which is sketched in this paragraph, we do not need for it to be literally a presupposition; the only important point is that it should project out of the scope of negation. 
Super monsters II

world of evaluation. If this inference is preserved in the scope of negative expressions, we might obtain two effects:

- First, a negative sentence such as (89a') should be somewhat deviant to begin with. The reason is that it could only make sense with the help of local accommodation, for otherwise the sentence would both (i) assert that John never shows any kindness in the relevant situations, and (ii) that there is an iconic map between the role-shifted clause and some aspects of the situations that verify it.

- Second, we would expect to find the same problems in (89a), together with another one specifically triggered by $A N Y$ : when the positive inference triggered by Action Role Shift is taken into account, $A N Y$ is presumably not in a negative environment any more. Now it could be thought that this problem reduces to the first one, namely to the need to appeal to local accommodation to make the example coherent. But in other languages this is not so: intervention effects triggered by presuppositions, studied in great detail in Homer 2010, do seem to make their effects felt even in examples that facilitate local accommodation. A French example is given in (91). (91a) displays local accommodation in the scope of negation, and no NPI; (91b) is similar, except that a chance ('une chance') has been replaced with the NPI the slightest chance ('la moindre chance') — and the result is degraded.

(91) a. Pierre ne s'aperçoit pas que Marie a une chance de gagner, parce qu'elle n'a aucune chance.

Pierre NE SE notice not that Marie has a chance to win, because that she NE has no chance.

'Pierre doesn't notice that Marie has a chance to win, because she has no chance to win.'

b. ?Pierre ne s'aperçoit pas que Marie a la moindre chance de gagner, parce qu'elle n'a aucune chance.

Pierre NE SE notice not that Marie has the slightest chance to win, because that she NE has no chance.

Intended: 'Pierre doesn't notice that Marie has a (literally: any) chance to win, because she has no chance to win.'

Now in Section 2.1 we assumed that $A N Y$ in Attitude Role Shift was prohibited because of the quotational component of the sentence, rather than because of an intervention effect triggered by a presupposition-like inference. If the present analysis of the deviance of $A N Y$ in Action Role Shift is on the right track, we will have to (i) extend it to Attitude Role Shift, and thus lose an argument for the quotational 
component of the latter; or alternatively (ii) explain why the intervention effect is not expected to arise in Attitude Role Shift. Our data do not allow us to decide: if (ii) is correct, we would expect that (90a') is significantly better than (89a'). While there is a contrast, our data are certainly not sufficient to license a firm conclusion.

\section{B Iconically Enriched Language: Syntax}

We provide below a more formal definition of the syntax needed to provide the formal derivations cited in the text.

\section{B.1 Iconic enrichment}

We start from base language L produced by a Phrase Structure Grammar with only unary and binary branching and where constituents can be annotated with semantic types. $\mathrm{L}$ can be extended into an iconically enriched language $\mathrm{L}^{+}$by applying the method in (92). (We add some informal explanations in parentheses in the relevant parts of the definitions.)

\section{(92) Iconic Enrichment of a Language}

Let $\mathrm{L}$ be a language obtained on the basis of a phrase-structure grammar $\mathrm{G}$ with only binary-branching and unary-branching nodes. We assume that constituents of $\mathrm{L}$ can be annotated as having types or as being abstractors. The iconic enrichment of $\mathrm{L}$ is the language $\mathrm{L}^{+}$generated by the grammar $\mathrm{G}^{+}$ obtained by adding to $\mathrm{G}$ all the rules of the form

a. $\quad L \rightarrow E^{i} F^{j}, F^{i} E, E F^{j}$ for $i, j \in \mathbb{N}$, if $L \rightarrow E F$ is a rule of $G$ for which (i) $\mathrm{E}$ or $\mathrm{F}$ has a type $\langle\mathrm{a}, \mathrm{b}\rangle$ that 'ends in $\mathrm{t}$ ' 59 , and its sister either has type a, or (ii) $\mathrm{E}$ or $\mathrm{F}$ has a type that 'ends in $\mathrm{t}$ ', and its sister is an abstractor; (iconic enrichment is allowed when a functor of a type that 'ends in t' is applied to an argument, or when a constituent of a type that 'ends in t' undergoes abstraction)

b. $\quad \mathrm{L}^{\mathrm{i}} \rightarrow \mathrm{C}$ for $\mathrm{i} \in \mathbb{N}$, if $\mathrm{L} \rightarrow \mathrm{C}$ is a rule of $\mathrm{G}$ (where $\mathrm{C}$ may be one or two expressions), and $\mathrm{L}$ of type $\mathrm{t}$

(expressions of type $t$ are in effect ones that take the world/situation parameter as an argument, hence they can be iconically enriched)

Importantly, iconic enrichments can be added at the level of words or of entire constituents: we do not require that they should only arise at the lexical level.

To illustrate, consider a base language generated by the grammar in (93).

59 See fn. 36. 
Super monsters II

(93) $\mathrm{S}_{\mathrm{t}} \rightarrow \mathrm{DP}_{\mathrm{e}} \mathrm{VP}_{\mathrm{et}}$

$\mathrm{DP}_{\mathrm{e}} \rightarrow \mathrm{D}_{\langle\mathrm{et}, \mathrm{e}\rangle} \mathrm{N}_{\mathrm{et}}$

$\mathrm{VP}_{\text {et }} \rightarrow \mathrm{V}_{\mathrm{i} \text { et }}$

$\mathrm{D}_{\langle\text {et,e }\rangle} \rightarrow$ POSS-1 ${ }_{\langle\text {et,e }\rangle}$

$\mathrm{N}_{\text {et }} \rightarrow$ GROUP $_{\text {et }}$

$\mathrm{V}_{\mathrm{i} \text { et }} \rightarrow \mathrm{GROW}_{\text {et }}$

Among the rules that (92) allows us to add are those in (94) (because $D P_{e} V P_{e t}$ falls under (92a)i).

$$
\mathrm{S}_{\mathrm{t}} \rightarrow \mathrm{DP}_{\mathrm{e}} \mathrm{VP}_{\mathrm{et}}{ }^{\mathrm{k}} \text { for } \mathrm{k} \geq 0
$$

This will allow us to generate for MY GROUP GROW the derivation tree given in (95); we have boldfaced the iconic index $k$ in order to call attention to it (for legibility we omit type subscripts).

$$
\text { [s[DP[D MY] [N GROUP]] [ }{ }_{\mathrm{VP}^{\mathbf{k}}}\left[\mathrm{v}_{\mathrm{i}}\right. \text { GROW]]] }
$$

By similar reasoning, we can also add the rules in (96) (because $D P_{e} V P_{e t}$ is of type $t$ and thus also falls under (92b)).

$$
\mathrm{S}_{\mathrm{t}}{ }^{\mathrm{k}} \rightarrow \mathrm{DP}_{\mathrm{e}} \mathrm{VP}_{\mathrm{et}} \text { for } \mathrm{k} \geq 0
$$

This will allow us to generate a derivation tree as in (97), which will be useful in case an iconic property, such as a happy face, applies to an entire clause.

$$
{ }_{S^{k}}\left[D P \left[D \text { MY] [N GROUP]] [vP [v } v_{i}\right.\right. \text { GROW]]] }
$$

\section{B.2 Appropriately simplified derivation trees}

In order the avoid multiplying semantic rules, we assume that the interpretation procedure takes as input simplified derivation trees, ones from which labels and non-branching nodes have been eliminated. But since the procedure outlined in (92) adds iconic indices to labels, we must ensure that these are preserved in the derivation trees that will eventually be interpreted. A procedure is outlined in (98).

\section{(98) Appropriately simplified derivation trees}

We assume that $\mathrm{L}^{+}$is a language obtained on the basis of a phrase-structure grammar $\mathrm{G}^{+}$defined as in (92). We call a derivation tree for $\mathrm{G}^{+}$'appropriately simplified' when it is transformed by (i) copying iconic indices from any nonbranching node $\mathrm{N}$ onto the closest branching node under $\mathrm{N}$, or onto the terminal node under $\mathrm{N}$ if $\mathrm{N}$ dominates no branching node; and then by (ii) deleting all non-branching nodes. 
To illustrate, consider again the derivation tree we obtained for MY GROUP GROW in (95), repeated as (99a). In order to obtain an 'appropriately simplified' derivation tree, we start by copying the iconic index $k$ on $G R O W$, which is the terminal node under $V P^{k}$ (since there is no branching node under $V P^{k}$ ); after this is done, we remove the non-branching nodes - and obtain (45b), which can be interpreted as in Section 4.2.3.

(99) a. [s[DP[D MY] [N GROUP]] [ $\mathrm{VP}^{\mathrm{k}}\left[\mathrm{V}_{\mathrm{i}}\right.$ GROW]]]]

b. [MY GROUP] GROW ${ }^{\mathbf{k}}$

Suppose now that the iconic component to be interpreted is a happy face on the entire clause, as in (100a). We take this to correspond to an iconic index $k$ that appears on the matrix node, as in $\left(100 \mathrm{a}^{\prime}\right)(=(97))$. After the index $k$ is copied onto the first branching node under $S$, and the non-branching nodes have been removed, we obtain (100b).
a. $\frac{:-)}{[[\mathrm{MY} \text { GROUP] GROW] }}$

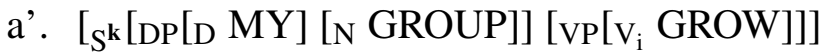
b. [[MY GROUP] GROW $]^{\mathbf{k}}$

\section{Role Shift Operators and Quotation}

In Part I (Appendix IV) of the present study, we defined an alternative Role Shift operator, which unlike our 'official' one is extensional, i.e. triggers abstraction over an individual argument but not abstraction over a world argument. We now explain why this alternative operator - which is in some respects simpler than the one we used - would yield difficulties in the statement of our iconic conditions.

The semantics of the alternative operator is defined in (101). Because it is purely extensional, in attitude reports it must be combined with an intensional operator, which we notated $O p$.

(101) Semantics of $\frac{R S_{i}}{I P}$, written as $R S_{i} I P$

Let $\mathrm{c}$ be a context, $\mathrm{s}$ an assignment function and $\mathrm{w}$ a situation. Then for any index $\mathrm{i}$ and clause $I P$, $\llbracket \mathrm{RS}_{\mathrm{i}} \mathrm{IP} \rrbracket^{\mathrm{c}, \mathrm{s}, \mathrm{w}}=1$ iff $\llbracket \mathrm{IP} \rrbracket^{\langle\mathrm{s}(\mathrm{i}), \mathrm{w}\rangle, \mathrm{s}, \mathrm{w}}=1$ 
Super monsters II

(102) For any clause $F$, context c, assignment function s and situation w, $\llbracket O p_{i} F \rrbracket^{c, s, w}=\lambda x^{\prime}{ }_{e} \lambda w^{\prime}{ }_{s} \cdot \llbracket F \rrbracket^{c, s[i \rightarrow x '], w '}$

With these operations in place, our analysis of Attitude Role Shift relied on Logical Forms such as that in (103):

\section{IX-a SAY Op $\mathrm{RS}_{\mathrm{a}}$ [IX-1 WILL-LEAVE]}

But a difficulty arises when we posit that role-shifted clauses must be interpreted maximally iconically. Unless we give a rather odd statement of this maximization rule, we will get the result that the role-shifted clause excluding the operator $O p$ is interpreted maximally iconically, hence a Logical Form such as (104), where the index 0 is quotational (for legibility, the iconically interpreted part is boldfaced).

\section{IX-a SAY Op ${ }_{a}\left[\text { RS }_{\mathbf{a}}[\mathbf{I X - 1} \text { WILL-LEAVE }]\right]^{0}$}

In the system developed in the text (specifically, in (55)), quotational indices can only appear on expressions that have a type $\langle\mathrm{s}, \mathrm{t}\rangle$ or $\langle\mathrm{e},\langle\mathrm{s}, \mathrm{t}\rangle\rangle$, which is not the case here. But even if we made the system more liberal, we would have a problem when we apply (102) to the embedded clause, as the iconic component of the role-shifted clause would be computed 'too low', within the scope of the attitude report:

$$
\begin{aligned}
& \llbracket \mathrm{Op}_{\mathrm{a}}\left[\mathbf{R S}_{\mathbf{a}}[\mathbf{I X}-\mathbf{1} \text { WILL-LEAVE }]\right]^{0} \rrbracket^{\mathrm{c}, \mathrm{s}, \mathrm{w}}
\end{aligned}
$$

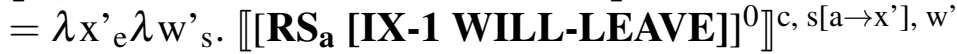

$$
\begin{aligned}
& =\lambda \mathrm{x}_{\mathrm{e}}{ }_{\mathrm{e}} \lambda \mathrm{w}{ }_{\mathrm{s}} . \ldots 1 \text { iff } \ldots \llbracket \llbracket\left[\mathbf{R S}_{\mathbf{a}}[\mathbf{I X}-\mathbf{1} \text { WILL-LEAVE }]\right]^{0} \rrbracket^{\mathrm{c}, \mathrm{s}\left[\mathrm{a} \rightarrow \mathrm{x}{ }^{\prime}\right], \mathrm{w}{ }^{\prime}}=1
\end{aligned}
$$

This would yield a meaning according to which the agent said that he would leave, and said that this proposition was expressed by the very words that appear in the embedded clause. But what we want is for the latter component not to be part of the content of what was said.

Importantly, the extensional Role Shift operator in (101) must be in the scope of an abstractor over individuals in order to yield a De Se reading, and hence a version of the problem we noted above is bound to arise with this particular definition. By contrast, the problem could be circumvented if we gave the Role Shift operator the semantics in (106), supplemented with one of the intensional operators defined in (107a) and (107b). With the Logical Form in (108), the corresponding meanings for the embedded clause are derived in (109a) and (109b). The key for our purposes is that in (108a) the Role Shift operator is above the abstraction operator, hence if the entire role-shifted clause carries a quotational index, as in (108b), we will obtain the same kind of result as in our 'official' system, namely that the agent uttered the role-shifted expression (rather than said that he uttered it). 
(106) For any clause $I P$, context c, assignment function s and situation w, $\llbracket \mathrm{RS}_{\mathrm{i}} \mathrm{IP} \rrbracket^{\mathrm{c}, \mathrm{s}, \mathrm{w}}=\lambda \mathrm{x}^{\prime}{ }_{\mathrm{e}} \cdot \llbracket \mathrm{IP} \rrbracket^{\left\langle\mathrm{x}^{\prime}, \mathrm{c}_{\mathrm{w}}\right\rangle, \mathrm{s}, \mathrm{w}}$

(107) For any clause $F$, context c, assignment function s and situation w,

a. $\quad \llbracket \mathrm{Op}^{*}{ }^{\mathrm{F}} \rrbracket^{\mathrm{c}, \mathrm{s}, \mathrm{w}}=\lambda \mathrm{w}^{\prime}{ }_{\mathrm{s}} \cdot \llbracket \mathrm{F} \rrbracket^{\left\langle\mathrm{c}_{\mathrm{a}}, \mathrm{w}^{\prime}\right\rangle, \mathrm{s}, \mathrm{w}^{\prime}}$

b. $\quad \llbracket \mathrm{Op}^{* *} \mathrm{~F} \rrbracket^{\mathrm{c}, \mathrm{s}, \mathrm{w}}=\lambda \mathrm{x}_{\mathrm{s}}{ }_{\mathrm{s}} \cdot \llbracket \mathrm{F} \rrbracket^{\mathrm{c}, \mathrm{s}, \mathrm{w}}$

a. IX-a SAY RS $\mathrm{a}_{\mathrm{a}}$ Op [IX-1 WILL-LEAVE]

b. IX-a SAY $\left[\mathrm{RS}_{\mathrm{a}} \mathrm{Op}[\mathrm{IX}-1 \text { WILL-LEAVE] }]^{0}\right.$

$$
\begin{aligned}
& \text { a. } \llbracket \mathrm{RS}_{\mathrm{a}} \mathrm{Op}^{*}[\mathrm{IX}-1 \text { WILL-LEAVE }] \rrbracket^{\mathrm{c}, \mathrm{s}, \mathrm{w}} \\
& =\lambda \mathrm{x}^{\prime}{ }_{\mathrm{e}} \cdot \llbracket \mathrm{Op}^{*}[\mathrm{IX}-1 \text { WILL-LEAVE }] \rrbracket^{\left\langle\mathrm{x}^{\prime}, \mathrm{c}_{\mathrm{w}}\right\rangle, \mathrm{s}, \mathrm{w}} \\
& =\lambda \mathrm{x}{ }_{\mathrm{e}} \lambda \mathrm{w}^{\prime}{ }_{\mathrm{s}} \cdot{ } \text { 【IX-1 WILL-LEAVE } \rrbracket^{\left\langle\mathrm{x}^{\prime}, \mathrm{w}^{\prime}\right\rangle, \mathrm{s}, \mathrm{w}} \\
& \text { b. } \llbracket \mathrm{RS}_{\mathrm{a}} \mathrm{Op}^{* *}[\mathrm{IX}-1 \text { WILL-LEAVE }] \rrbracket^{\mathrm{c}, \mathrm{s}, \mathrm{w}} \\
& =\lambda \mathrm{x}^{\prime}{ }_{\mathrm{e}} \cdot \llbracket \mathrm{Op}^{* *}[\mathrm{IX}-1 \text { WILL-LEAVE }] \rrbracket^{\left\langle\mathrm{x}^{\prime}, \mathrm{c}_{\mathrm{w}}\right\rangle, \mathrm{s}, \mathrm{w}} \\
& =\lambda \mathrm{x}{ }_{\mathrm{e}} \lambda \mathrm{w}^{\prime}{ }_{\mathrm{s}} \cdot \llbracket \text { IX-1 WILL-LEAVE } \rrbracket^{\left\langle\mathrm{x}^{\prime}, \mathrm{c}_{\mathrm{w}}\right\rangle, \mathrm{s}, \mathrm{w}{ }^{\prime}}
\end{aligned}
$$

The meaning obtained in (109a) is just a centered proposition, and could be directly integrated into standard analyses of De Se readings and shifted indexicals; note that the overall effect of the operators is to manipulate the individual and situation coordinates of the context of evaluation of the embedded clause, as well as its situation of evaluation. But this is obtained at the price of a somewhat non- standard meaning for the intensional operator in (107a), which simultaneously binds the situation parameter and the situation coordinate of the context parameter. The entry in $(107 \mathrm{~b})$ is definitely more common, but the meaning it gives for the embedded clause in (109b) is less standard: the combined effect of the two abstraction operators is to manipulate the individual but not the situation coordinate of the context of evaluation of the embedded clause, as well as its situation of evaluation; some adaptations would be needed to integrate this meaning into standard analyses of De Se readings and shifted indexicals.

Be that as it may, the definition in (106) has the advantage of yielding a simple and elegant treatment of Action Role Shift, with Logical Forms such as (110a): because the Role Shift operator triggers an individual abstraction, the role-shifted clause can take an individual argument. 
Super monsters II

(110) a. IX-a RS ${ }_{a}\left[1-W A L K-W I T H-E N E R G Y ~ \varnothing_{1}\right]$

b. IX-1 $\lambda$ a RS $\mathrm{R}_{\mathrm{a}}\left[1-\mathrm{WALK}-\mathrm{WITH}-\mathrm{ENERGY} \varnothing_{1}\right]$

c. $\quad \mathrm{w}^{*} \mathrm{IX}-\mathrm{a} \mathrm{RS}_{\mathrm{a}}\left[1-\mathrm{WALK}-\mathrm{WITH}-\mathrm{ENERGY}(\mathrm{CL}-\mathrm{ONE}) \varnothing_{1}\right]$

By contrast, with the extensional operator defined in (101) and in Appendix IV of Part I, we had to posit the Logical Form in (110b), where an additional individual abstraction operator is needed to guarantee that the role-shifted clause can take an individual argument. The present implementation also differs from the 'official' analysis given in the main text, where the role-shifted clause can take an individual argument, but must be provided with a situation argument in order to yield a truth value, as in (110c).

\section{References}

Anand, Pranav. 2006. De de se: University of California, Santa Cruz dissertation.

Anand, Pranav \& Andrew Nevins. 2004. Shifty operators in changing contexts. In Semantics and Linguistic Theory (SALT) 14, 20-37. Ithaca, NY: Cornell University.

Barwise, John. 1988. The situation in logic. Stanford: CSLI.

Cappelen, Herman \& Ernest Lepore. 1997. Varieties of quotation. Mind 106. 429-450. https://doi.org/10.1093/mind/106.423.429.

Chierchia, Gennaro. 1987. Anaphora and attitudes de se. In Bartsch, van Benthem \& van Emde Boas (eds.), Language in context, Dordrecht, Netherlands: Foris.

Clark, Herbert H. \& Richard G. Gerrig. 1990. Quotations as demonstrations. Language 66. 764-805. https://doi.org/10.2307/414729.

Davidson, Kathryn. 2015. Quotation, demonstration, and iconicity. Linguistics and Philosophy https://doi.org/10.1007/s10988-015-9180-1.

Elbourne, Paul. 2005. Situations and individuals. Boston, MA: MIT Press. Current Studies in Linguistics.

Engberg-Pedersen, Elisabeth. 1993. Space in Danish Sign Language: The semantics and morphosyntax of the use of space in a visual language. Hamburg: Signum.

Engberg-Pedersen, Elisabeth. 1995. Point of view expressed through shifters. In K. Emmorey \& J. Reilly (eds.), Language, gesture, and space, 133-154. Hillsdale, NJ: Lawrence Erlbaum Associates.

Geurts, Bart \& Emar Maier. 2005. Quotation in context. Belgian Journal of Linguistics 17(1). 109-128. https://doi.org/10.1075/bj1.17.07geu.

Heim, Irene. 1983. On the projection problem of presuppositions. In West Coast Conference on Formal Linguistics (WCCFL) 2, 114-125. https://doi.org/10. 1002/9780470758335.ch10. 
Herrmann, Annika \& Markus Steinbach. 2012. Quotation in sign languages - a visible context shift. In I. van Alphen \& I. Buchstaller (eds.), Quotatives: Cross-linguistic and cross disciplinary perspectives, .

Homer, Vincent. 2010. Polarity and modality: UCLA dissertation.

Klima, Edward \& Ursula Bellugi. 1979. The signs of language. Cambridge, MA: Harvard University Press.

Koulidobrova, Elena \& Kathryn Davidson. 2015. Watch the attitude: Role-shift and embedding in ASL. In Proceedings of sinn und bedeutung, Goettingen, September 2014.

Kratzer, Angelika. 2014. Situations in natural language semantics. In Edward N. Zalta (ed.), The Stanford encyclopedia of philosophy, Spring 2014 edn. http: //plato.stanford.edu/archives/spr2014/entries/situations-semantics/.

Kuhn, Jeremy. 2015. Asl loci: Variables or features? Journal of Semantics https: //doi.org/10.1093/jos/ffv005.

Lewis, David. 1979. Attitudes de dicto and de se. The Philosophical Review 88. 513-543. https://doi.org/10.2307/2184843.

Liddell, Scott K. \& Melanie Metzger. 1998. Gesture in sign language discourse. Journal of Pragmatics 30. 657-697. https://doi.org/10.1016/S0378-2166(98) 00061-7.

Lillo-Martin, Diane. 1995. The point of view predicate in American Sign Language. In Karen Emmorey \& Judy Reilly (eds.), Language, gesture, and space, 155-170. Hillsdale, NJ: Lawrence Erlbaum Associates.

Lillo-Martin, Diane. 2012. Utterance reports and constructed action. In R. Pfau, M. Steinbach \& B. Woll (eds.), Sign language: An international handbook, 365-387. De Gruyer Mouton.

Maier, Emar. 2014a. Mixed quotation. Manuscript, University of Groningen.

Maier, Emar. 2014b. Mixed quotation: The grammar of apparently transparent opacity. Semantics and Pragmatics 7(7). 1-67. https://doi.org/10.3765/sp.7.7.

Pearson, Hazel. 2012. The sense of self: Topics in the semantics of de se expressions: Harvard dissertation.

Quer, Josep. 2005. Context shift and indexical variables in sign languages. In Semantics and Linguistic Theory (SALT) 15, Ithaka, NY: CLC Publications.

Quer, Josep. 2013. Attitude ascriptions in sign languages and role shift. In Leah C. Geer (ed.), Texas Linguistics Society (TLS) 13, .

Recanati, Francois. 2001. Open quotation. Mind 110. 637-687. https://doi.org/10. 1093/mind/110.439.637.

Recanati, Francois. 2008. Open quotation revisited. Philosophical Perspectives 22. 443-471. https://doi.org/10.1111/j.1520-8583.2008.00153.x.

Rooth, Mats \& Barbara Partee. 1982. Conjunction, type ambiguity and wide scope “or”. In D. Flickenger, M. Macken \& N. Wiegand (eds.), West Coast Conference 
Super monsters II

on Formal Linguistics (WCCFL) 1, 1-10. Linguistics Department, Stanford University.

Sandler, Wendy \& Diane Lillo-Martin. 2006. Sign language and linguistic universals. Cambridge University Press.

Schlenker, Philippe. 2003. A plea for monsters. Linguistics \& Philosophy 26. 29-120. https://doi.org/10.1023/A:1022225203544.

Schlenker, Philippe. 2011. Indexicality and de se reports. In von Heusinger, Maienborn \& Portner (eds.), Semantics, vol. 2, Mouton de Gruyer.

Schlenker, Philippe. 2014. Iconic features. Natural Language Semantics 22(4). 299-356. https://doi.org/10.1007/s11050-014-9106-4.

Schlenker, Philippe. 2017. Super monsters I: Attitude and Action Role Shift in sign language. Semantics and Pragmatics 10(9). https://doi.org/10.3765/sp.10.9.

Schlenker, Philippe, Jon Lamberton \& Mirko Santoro. 2013. Iconic variables. Linguistics and Philosophy 36(2). 91-149. https://doi.org/10.1007/s10988-0139129-1.

von Stechow, Arnim \& Thomas Ede Zimmermann. 2005. A problem for a compositional treatment of de re attitudes. In Gregory N. Carlson \& Francis Jeffry Pelletier (eds.), Reference and quantification: The Partee effect, 207-228. Stanford: CSLI.

Supalla, Ted. 1982. Structure and acquisition of verbs of motion and location in American Sign Language: University of California, San Diego dissertation.

Zucchi, Sandro, Carlo Cecchetto \& Carlo Geraci. 2012. Event descriptions and classifier predicates in sign languages. In Formal and experimental advances in sign language theory, Venice, Italy. 